ISSN: 0514-7336

DOI: http://dx.doi.org/10.14201/zephyrus20188293117

\title{
SOBRE LA ESTRUCTURA POBLACIONAL DE LAS SOCIEDADES DEL SUR DEL BRONCE VALENCIANO
}

\section{On the population structure of the societies from the South of the Valencian Bronze Age area}

\author{
Francisco Javier Jover Maestre*, Sergio Martínez Monleón** y Juan Antonio López Padilla*** \\ * Instituto Universitario de Investigación en Arqueología y Patrimonio Histórico (INAPH). Universidad de Alicante. \\ Aptdo. 99.03080 Alicante. Correo-e: javier.jover@ua.es. ID ORCID: 0000-0001-5213-2361 \\ ** Dpto. de Prehistoria, Arqueología, H. a Antigua y Filologías Griega y Latina. Universidad de Alicante. Aptdo. \\ 99.03080Alicante.Correo-e: sergio.mmonleon@ua.es.ID ORCID:0000-0002-6352-4499 \\ *** Museo Arqueológico Provincial de Alicante (MARQ). Plaza Gómez Ulla, s/n. 03013 Alicante. Correo-e: japadi@ \\ diputacionalicante.es. ID ORCID: 0000-0002-1506-4731
}

Recepción: 14/12/2017; Revisión: 11/02/2018; Aceptación: 26/06/2018

Resumen: En el presente artículo se pretende caracterizar de forma más precisa el modelo de implantación, en el espacio geográfico del denominado Bronce Valenciano, de algunas de las sociedades concretas que lo ocuparon entre finales del III y mediados del II milenio cal AC. Se proponen algunas hipótesis acerca de su organización poblacional, social y política, intentando explicar su conformación y transformación a lo largo de dicho periodo. Así, a partir de la valoración de diversas variables de importancia en la caracterización del patrón de asentamiento, como son el tamaño o extensión superficial de los yacimientos, la altura relativa o las condiciones topográficas del entorno inmediato, y de las características de los yacimientos excavados hasta la fecha, se ha desarrollado una propuesta de representación del poblamiento en el área meridional del Bronce Valenciano. Los resultados preliminares del estudio invitan a matizar la imagen mantenida hasta ahora de un territorio densamente ocupado por un gran número de pequeńos asentamientos, y a contemplar, en cambio, un espacio social cambiante a lo largo del tiempo e integrado por emplazamientos de distinto origen, duración y orientación funcional.

Palabras clave: Edad del Bronce; Este peninsular; territorio; estructura política; desarrollo social.

ABstract: This article aims to characterize more accurately the settlement model, in the geographic space of the so-called Valencian Bronze Age area, of some of the specific societies that occupied it between the end of the III millennium BC and the middle of the II millennium BC. Some hypotheses about their population, social and political structure are proposed, trying to explain their conformation and transformation throughout this period. Thus, based on the assessment of various variables such as the size of the settlements; relative height, the topographic conditions of the immediate environment and characteristics of the excavated sites, a proposal has been developed on the settlement pattern in the Valencian Bronze Age area. The preliminary results of the study suggest a different image as the one maintained so far of a territory densely occupied by a large number of small settlements. Instead, we start to discern a changing social space over time and composed of sites of different origin, duration and functional orientation.

Key words: Bronze Age; Peninsular Eastern; territory; political structure; social development. 


\section{Introducción ${ }^{1}$}

Desde que en la década de 1950 se propusiera la existencia de diversas áreas culturales para la Edad del Bronce en el mediodía de la Península Ibérica (Tarradell, 1950, 1965), las investigaciones arqueológicas se encaminaron a la caracterización secuencial y material de los grupos arqueológicos de El Argar, el Bronce del Suroeste, el Bronce de La Mancha y el Bronce Valenciano (Tarradell, 1963; Schubart, 1975; Lull, 1983; Martí, 1983; Nájera, 1984; Hernández, 1986; Martín et al., 1993). Más recientemente, la introducción de nuevos planteamientos teóricos orientó la investigación hacia la corroboración de diversas hipótesis de tipo identificatorio, relativas al grado de desarrollo social (Lull y Estévez, 1986; Martínez Navarrete, 1989; Chapman, 1990). Mientras que para El Argar se planteaban distintas propuestas -sociedad de tipo jefatura (Gilman, 1981; Chapman, 1990; Ramos, 2013), sociedad de clases (Arteaga, 2000; Cámara y Molina, 2011) o de carácter estatal (Lull et al., 2011)-, para el Bronce Valenciano y de La Mancha se ha planteado su identificación sociológica con sociedades segmentarias (De Pedro y Martí, 2004; Brodsky et al., 2013), como sociedades tribales en apariencia (Jover, 1999) o como sociedades jerarquizadas (Bernabeu et al., 1989; Gil-Mascarell, 1995; Nájera y Molina, 2004).

Los principales indicadores empleados en la validación de estas hipótesis han sido las prácticas funerarias (Lull y Estévez, 1986; Lull et al., 2011; Nájera et al., 2012), el control de la producción (Risch, 2002; Lull et al., 2010; Schuhmacher, 2012) y el estudio del patrón de asentamiento, desde el que se ha pretendido inferir la existencia de diversos niveles de jerarquización poblacional (Nocete, 1989; Arteaga, 2000; Cámara et al., 2007; Fernández-Posse et al., 2008; Lull et al., 2011; Legarra, 2013; Martínez Monleón, 2014).

1 El presente trabajo forma parte del proyecto de investigación Espacios sociales y espacios de frontera durante el Calcolitico y la Edad del Bronce en el Levante de la Peninsula Ibérica (HAR2OI 6-76586-P), financiado por el Ministerio de Economía y Competitividad.
En el presente artículo pretendemos avanzar en el estudio de este último aspecto, analizando las características del poblamiento en el ámbito geográfico de lo que, tradicionalmente, se ha venido definiendo como área cultural del Bronce Valenciano $^{2}$, así como proponer algunas hipótesis sobre la estructura social y política y el proceso histórico involucrados en su conformación.

\section{Los primeros ensayos de caracterización del patrón de asentamiento en las sociedades del Bronce Valenciano}

Desde la década de 1980 hasta la actualidad se ha llevado a cabo una intensa labor de prospección en las diversas cuencas fluviales que integran las tierras valencianas (Martínez Pérez, 1985; Pascual, 1990; Moraño y García, 1991; Cerdà, 1994; Ripollés, 1994; Palomar, 1995; Esquembre, 1997; Ribera y Pascual, 1997; Pérez Botí, 2000; Esquembre y Simón, 2001; García Borja, 2004; Soriano, 2004; García Guardiola, 2006; Cebrián, 2008/09, entre otros). Estos trabajos han venido a concretar, sobre espacios geográficos acotados, aquellas prístinas propuestas que señalaban que el Bronce Valenciano (Fig. 1) se caracterizaba por la existencia de una multitud de pequeños poblados ubicados en lo alto de cerros y laderas montañosas (Tarradell, 1963; Martí, 1983).

2 Las distintas sociedades que se incluirían bajo lo que historiográficamente se conoce como Bronce Valenciano (Jover, 1999) también han sido englobadas bajo Bronce Íbero-Levantino (Castro et al., 1996: 135) o Bronce Ibérico (Almagro, 1997: 224). En ambos casos, dichas propuestas no significaron más que un cambio de etiqueta con la intención de integrar bajo un nuevo término realidades arqueológicas muy diversas, ampliamente repartidas por un espacio geográfico más amplio del este peninsular que el inicialmente propuesto para el Bronce Valenciano, e incluso, en muchos casos, peor caracterizadas que la propuesta inicial de Tarradell (1963: 62; 1965: 427). En nuestro caso, para este trabajo asumimos parte de las reflexiones de Gil-Mascarell (1995: 69) en relación con el uso del término 'Bronce Valenciano' -con la excepción del marco territorial que consideró para el mismo-y nos reafirmamos en los planteamientos realizados hace ya unos años con respecto a su contenido (Jover, 1999: 56-68). 


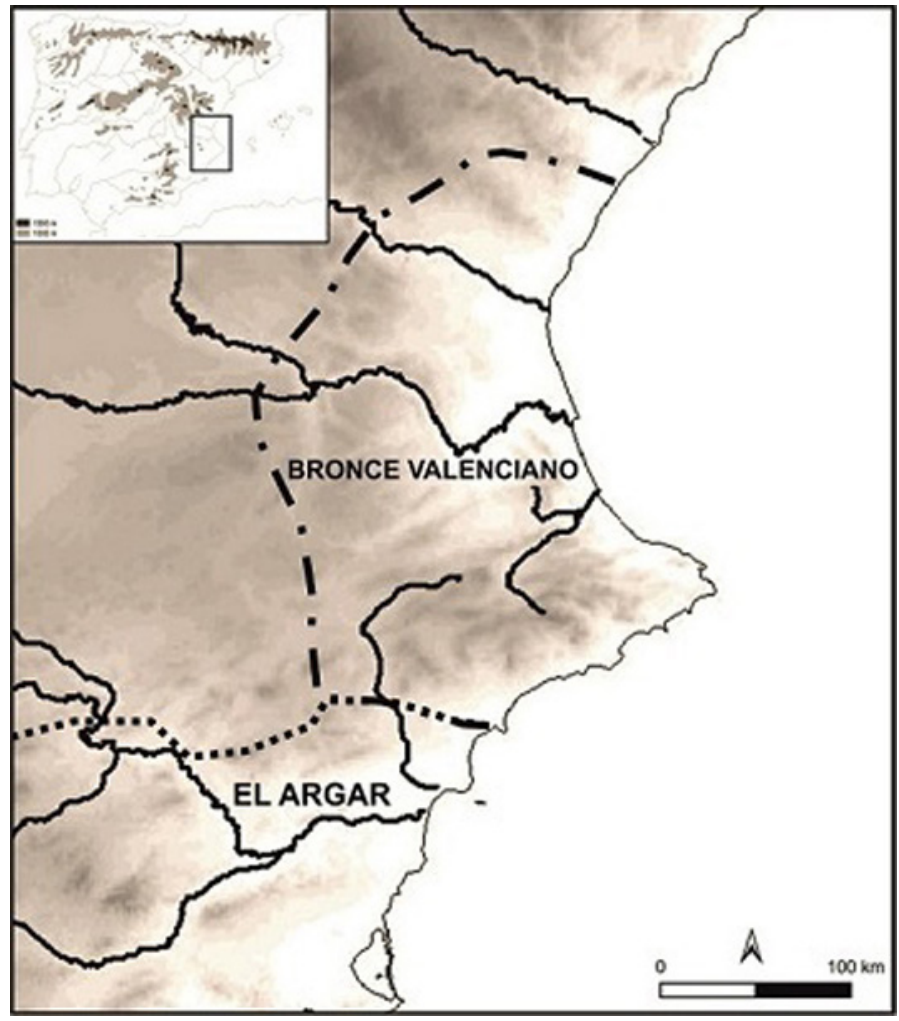

FIG. 1. Mapa con indicación del área del Bronce Valenciano en relación con El Argar.

En este sentido, han pasado ya dos décadas desde la formulación de las primeras propuestas interpretativas sobre la dinámica del poblamiento, esencialmente basadas en el análisis de algunos territorios específicos. Así, M. S. Hernández (1997) razonaba que el amplio número de yacimientos de pequeño tamaño detectados en la cuenca media del río Vinalopó debían de responder a un modelo de asentamientos de corta duración orientados económicamente a una agricultura itinerante, favorecida por una baja densidad demográfica y una amplia disponibilidad de terreno agrícola. Todo ello fomentaría la movilidad de los grupos y el abandono y creación de núcleos de población que, por tanto, no serían siempre contemporáneos. Por su parte, M. A. Esquembre (1997) introducía factores de orden funcional en relación con la ubicación de los asentamientos. A su juicio, el elevado número de emplazamientos localizados en espacios montańosos, alejados de tierras aptas para el cultivo y con muy diverso grado de visibilidad, se podría explicar en relación con la explotación de recursos silvopastoriles.

Por esas mismas fechas, otros estudios basados en el análisis de la distribución, tamaño y localización de los asentamientos en la cuenca del río Vinalopó permitían observar la existencia de diversas agrupaciones significativas que, posteriormente, fueron matizadas con la aplicación de diversas técnicas de análisis espacial, como los polígonos de Thiessen y el coeficiente del vecino más próximo. Los resultados obtenidos en aquellos años mostraban la configuración durante la primera mitad del II milenio cal AC de un patrón donde los asentamientos de mayor tamaño -entre 0,1 y 0,4 ha- se distribuían de manera uniforme, ordenada y casi equidistante entre ellos, mientras los de menor tamaño se disponían agrupados en torno a los primeros (Jover y López, 1999: 241).

Por otro lado, las excavaciones emprendidas en diversos asentamientos mostraban que las estructuras que habían hecho pensar en la existencia de poblados amurallados correspondían más bien a muros de cierre o a plataformas de aterrazamiento (De Pedro y Martí, 2004; Jover y López, 2016), carentes de un carácter expresamente defensivo. En cualquier caso, denotaban la inversión de una importante cantidad de trabajo en el acondicionamiento de los espacios de hábitat, con la voluntad de permanecer ocupando un mismo emplazamiento de forma indefinida (Jover, 1999: 145-148).

A la luz de estos datos, se consideró la existencia de una estructura poblacional estable, caracterizada por una progresiva consolidación de los núcleos de mayor tamaño desde los momentos iniciales de la Edad del Bronce hasta, al menos, mediados del II milenio cal AC (Jover y López, 2016). Sin embargo, esta propuesta carecía de apoyos empíricos firmes de carácter estratigráfico y cronológico para ser validada o refutada. Se hacía necesario emprender la excavación de diferentes tipos de asentamientos en un mismo territorio para iniciar el necesario proceso evaluatorio. 
Los últimos años han servido para incrementar las bases documentales en diferentes aspectos. La excavación de un buen número de enclaves se ha visto acompañada de la ampliación de las prospecciones $^{3}$ y del análisis territorial (De Pedro y Soler, 2015; Jover y López, 2016). Estos trabajos siguen corroborando la ausencia de núcleos de la Edad del Bronce en el llano en esta zona de la península -entendiendo como tales asentamientos estables con cronologías comprendidas entre c. 2200/2150 y c. $1500 / 1450 \mathrm{cal}$ AC-, a diferencia de lo constatado en ciertas zonas del territorio argárico (Ayala, 1991; Lull et al., 2011) o de La Mancha (Mejías Moreno et al., 2015). Si en el primer caso su existencia se ha explicado en un marco de estrecha dependencia política y económica con respecto a los núcleos en altura (Risch, 2002), para la zona de La Mancha, en cambio, se ha aludido a un evento climático de una extrema aridez -el 4.2 Ka BP- que habría estimulado un control más directo sobre unos recursos hídricos cada vez más escasos (López Sáez et al., 2014; Mejías et al., 2015).

De este modo, para la zona del Bronce Valenciano y en el periodo comprendido entre finales del III y mediados del II milenio cal AC, se sigue corroborando que la inmensa mayoría de los yacimientos son de reducidas dimensiones, en ningún caso de más de 0,4 ha, y se localizan tanto en cerros ubicados en las distintas terrazas de las cuencas fluviales, como en crestas destacadas de las estribaciones montañosas que las delimitan, ocupando, en casos excepcionales, pequeños promontorios costeros (Gusi y Olària, 2014). A estos, debemos añadir la ocupación de cuevas, tanto asociadas a los anteriores como aisladas, ubicadas preferentemente en zonas montañosas. Estas han sido interpretadas como lugares de ocupación esporádica estrechamente relacionados con actividades silvopastoriles (Palomar, 1995; Fairén, 2001; García Borja et al., 2011).

Por último, uno de los progresos más significativos de los últimos años ha consistido en la aplicación

3 Por ejemplo, las series anuales sobre actuaciones arqueológicas en la provincia de Alicante y jornadas de arqueología de la Comunidad Valenciana que, aunque de forma incompleta, pueden ser consultadas on line. de la estadística bayesiana a amplias series de dataciones radiocarbónicas de tres asentamientos de larga ocupación ubicados en las tierras meridionales valencianas -Terlinques, Cabezo Pardo y Cabezo Redondo-, asociadas a los diferentes momentos de construcción, uso y abandono detectados, lo que ha hecho posible cotejar en el tiempo recurrentes dinámicas de ocupación, transformación y abandono, a las que se les puede atribuir un significado histórico. Para el periodo temporal aquí analizado son tres las fases que han podido concretarse entre c. 2200/2150 y 1500/1450 cal AC (Jover et al., 2014). Solo en Cabezo Redondo se reconoce una fase siguiente entre $1500 / 1450$ y $1300 / 1250$ cal AC, tradicionalmente denominada para la zona en estudio como Bronce Tardío (Hernández et al., 2016).

Consideramos que, disponiendo de estas nuevas bases empíricas y de un mejor y más actualizado conocimiento del registro arqueológico, resulta necesario volver a analizar las características del poblamiento en el Bronce Valenciano, centrando nuestra atención en las tierras meridionales, a día de hoy las mejor conocidas.

\section{Las tierras meridionales del Bronce Valenciano como ejemplo de análisis territorial}

\subsection{Consideraciones sobre las variables de análisis manejadas}

Desde nuestra perspectiva, toda nueva propuesta que pretenda explicar la dinámica del poblamiento en un territorio concreto, durante un periodo de tiempo dado, además de analizar todas las variables que se consideren relevantes para la caracterización del patrón de asentamiento, debería disponer también de información sobre las secuencias de ocupación de diversos asentamientos y contar con una fasificación lo más ajustada posible, en la que dimensionar temporalmente el proceso. En este sentido, son los territorios meridionales de las tierras valencianas -en concreto, buena parte de la cuenca de los ríos Vinalopó y Montnegre, situados en las proximidades de la zona septentrional de El Argar (Fig. 2)- los que ofrecen en la actualidad estos 


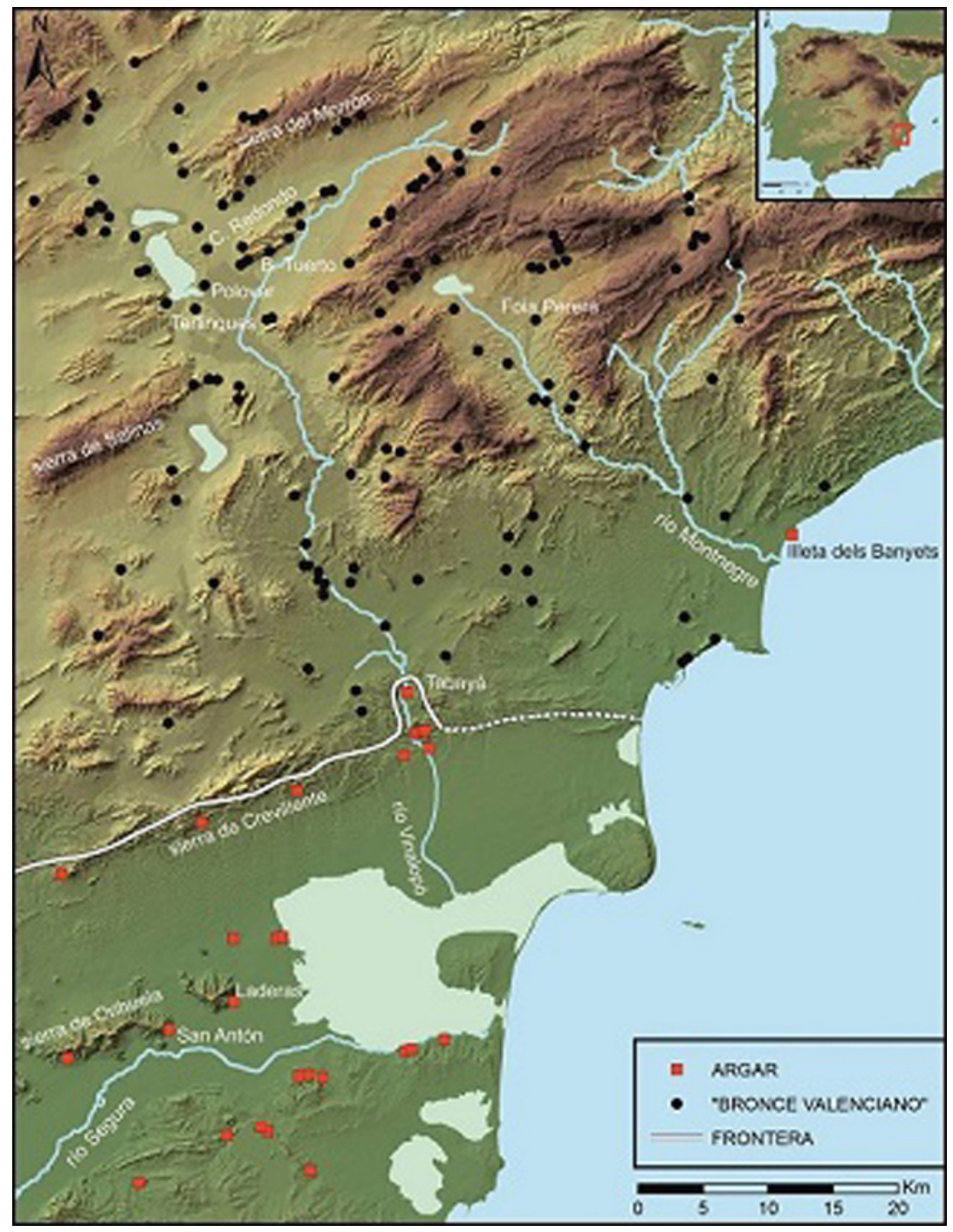

Fig. 2. Mapa con la distribución general de asentamientos argáricos (en rojo) y del Bronce Valenciano (en negro) e indicación mediante línea en blanco de los limites fronterizos hipotéticos entre ambos.

requerimientos empíricos. A la labor de prospección realizada en las últimas décadas cabe sumar la excavación de más de una decena de yacimientos ${ }^{4}$, algunos de ellos con amplias series radiocarbónicas (Jover et al., 2014).

En este estudio se han analizado los datos relacionados con el tamaño y la localización topográfica de

4 Cabezo Redondo, Terlinques, Barranco Tuerto, Cabezo del Polovar, Cerro del Rocín, Cerro de los Purgaticos, Peñón de la Zorra, La Horna, Lloma Redona, El Negret y Foia de la Perera. los yacimientos al aire libre documentados en diversos trabajos de prospección. Aunque estas dos variables pueden considerarse fundamentales, su análisis no permite, por sí solo, establecer un patrón de asentamiento, sino que deben considerarse en conjunto junto a otras. Sin embargo, hemos considerado pertinente avanzar en este trabajo algunas de las hipótesis que venimos manejando acerca del modelo de organización territorial de las sociedades en estudio, basándonos exclusivamente en las dos variables señaladas y en su contrastación con los datos obtenidos en la excavación y datación de algunos de ellos. Esto nos ha permitido matizar y corregir ciertos aspectos del modelo al que las primeras aparentemente apuntaban, obligando a considerar hipótesis alternativas que, en todo caso, deberán ser finalmente validadas o refutadas tras la aplicación de otras técnicas de análisis territorial en las que continuamos trabajando y que, dado el volumen de información resultante, requerirían para su exposición sobrepasar considerablemente la extensión máxima permitida para trabajos como el que aquí se presenta 5 .

En este sentido, la delimitación de las áreas de captación representadas en la Fig. 9 se ha realizado teniendo en cuenta como factores limitantes para el desplazamiento únicamente la pendiente y la existencia de espacios lacustres, generando un modelo de costes o fricción según las propuestas elaboradas en trabajos previos y considerando que un adulto en buen estado físico recorre aproximadamente unos $5 \mathrm{~km} / \mathrm{h}$ en un terreno llano (Martínez Monleón, 2014: 31, tab. 1). A partir de este ráster, se han evaluado las posibilidades económicas del entorno geográfico inmediato con la cartografía de capacidad de uso del suelo, a escala 1:50.000, elaborada por la coput de la Generalitat Valenciana (Antolín, 1998), 
Así, uno de los aspectos considerados clave en este estudio es el tamaño o superficie conservada de los yacimientos, que estimamos revelador de la magnitud e intensidad en la ocupación de un sitio y que ha sido considerado un indicador potencial de la existencia de centros políticos y de relaciones de dependencia entre asentamientos -jerarquización social- (Steponaitis, 1981; Feinman, 2011). Dado que numerosos factores pueden incidir en la distorsión de la extensión original de estos (Burillo y Peña, 1984; Burillo, 1996), ha sido necesario identificar la superficie actualmente conservada ${ }^{6}$ en los yacimientos y plantear su interpretación teórica, teniendo en cuenta los procesos que pueden incidir en su destrucción y/o ampliación por dispersión de los restos, principalmente de fragmentos cerámicos. En este sentido, la experiencia obtenida de la excavación de algunos de estos núcleos ha venido a corroborar que su tamaño real suele ser más reducido que la extensión superficial máxima estimada previamente. En algunos casos, como Barranco Tuerto (Jover y López, 1999), Cabezo del Polovar o Cerro de los Purgaticos (Jover et al., 2017), la extensión real del asentamiento una vez excavado se redujo entre un 20 y un 30\% sobre la estimación inicial del depósito sedimentario conservado a nivel superficial.

Otro factor analizado en este trabajo es la altura relativa de los asentamientos respecto del llano circundante, un indicador que creemos que aporta datos muy clarificadores sobre las estrategias de implantación en el territorio. Aunque la elección de un determinado emplazamiento no siempre hubo de estar orientada a maximizar el aprovechamiento de todas las condiciones que este podía ofrecer en cada caso, es razonable suponer que las características del mismo y de su entorno físico revelen qué factores -como, por ejemplo, la visibilidad o el coste de desplazamiento a las áreas de captación- se

agrupando las cinco categorías definidas en dos: capacidades de uso muy elevada, elevada y moderada, por un lado, y por otro las capacidades de uso baja y muy baja.

${ }^{6}$ Se entiende por superficie conservada el área en la que se observa la presencia de depósitos sedimentarios artificiales asociados a evidencias arqueológicas. Ello supone considerar para el caso aquí en estudio que la superficie estimada será siempre el tamaño máximo posible conservado. potencian dentro de los sistemas de ocupación del territorio, permitiendo, así, realizar valoraciones sobre la funcionalidad probable de los mismos. Frente a otros métodos de cálculo empleados para cuantificar esta variable (Nocete, 1996: 16-17; Burillo y López, 2005/06: 75-76), en este caso se han desarrollado dos procedimientos diferentes. Los valores se han obtenido tomando como referencia la altura máxima del yacimiento y su diferencia con respecto a la altura mínima $\left(\mathrm{H}_{\mathrm{r} 1}\right)$ y la altura media $\left(\mathrm{H}_{\mathrm{r} 2}\right)$ existente en el entorno de $1 \mathrm{~km}$.

\subsection{Datos sobre el tamaño y la altura relativa en las cuencas de los ríos Vinalopó y Montnegre}

Así, en el espacio geográfico considerado -que supone aproximadamente unos $2.700 \mathrm{~km}^{2}$ - se ha documentado un total de 151 yacimientos al aire libre (Fig. 3). De entre todos ellos, únicamente Cabezo Redondo ${ }^{7}$, ubicado en la cubeta de Villena, superaría con creces la media hectárea de extensión superficial. Aunque se trata de un núcleo de amplio desarrollo temporal, que abarca todo el II milenio

7 Cabezo Redondo es un asentamiento de compleja secuencia ocupacional cuya fundación parece remontarse a finales del III milenio cal AC y su abandono se cifra hacia el 1250 cal AC (Hernández et al., 2016; García Atiénzar, 2017: 139, fig. 9). A través de las observaciones de campo efectuadas, la extensión máxima superficial del área destinada al hábitat, la ladera sudoccidental, se sitúa en torno a los 6.000 $\mathrm{m}^{2}$. Por el momento, es muy difícil concretar cuál sería el tamaño o extensión ocupada en cada uno de los momentos de su secuencia, aunque a tenor de los datos publicados sería durante el Bronce Tardío o momentos posteriores a mediados del ir milenio cal Ac cuando adquiriría su máximo tamaño. A modo de hipótesis, se podría considerar que podría haber sido un asentamiento superior a los $1.000 \mathrm{o}$ $2.000 \mathrm{~m}^{2}$ en momentos previos al Bronce Tardío, pero este extremo es imposible contrastarlo mientras no se publiquen ampliamente los trabajos de excavación en curso. Lo mismo podemos considerar para el asentamiento de El Negret (Barciela et al., 2012: 128), cuyas excavaciones han puesto de manifiesto una secuencia de ocupación que podría iniciarse con anterioridad al $1600 \mathrm{cal}$ AC y claramente prolongarse, por dataciones, hasta casi el tránsito al I milenio cal AC. Determinar sus dimensiones en cada una de las fases de ocupación es igualmente imposible por el momento. 


\begin{tabular}{|c|c|c|c|c|c|c|}
\hline N. ${ }^{\circ}$ & Yacimiento & Municipio & $\begin{array}{c}\text { TAMAŃO } \\
\left(\mathrm{m}^{2}\right)\end{array}$ & $\begin{array}{l}\mathrm{H}_{\mathrm{RI}} \\
(\mathrm{m})\end{array}$ & $\begin{array}{l}\mathrm{H}_{\mathrm{k} 2} \\
(\mathrm{~m})\end{array}$ & Grupo \\
\hline 1 & Cerro de los Huesos & Caudete & 150 & 150 & 61 & 3 \\
\hline 2 & La Atalayica & Caudete & 150 & 138 & 29 & 3 \\
\hline 3 & Cerro Moro & Caudete & 500 & 141 & 31 & 3 \\
\hline 4 & Cabezo del Rosario & Caudete & 3000 & 146 & 87 & 1 \\
\hline 5 & Los Anteojos & Caudete & 200 & 209 & -35 & 3 \\
\hline 6 & Puntal de los Anteojos & Caudete & - & 223 & 16 & - \\
\hline 7 & Monteagudo & Caudete & 150 & 220 & 0 & 3 \\
\hline 8 & Peńa Horadada & Caudete & 300 & 163 & 96 & 3 \\
\hline 9 & $\begin{array}{l}\text { Loma de la Cueva de } \\
\text { la Arena }\end{array}$ & Caudete & 300 & 51 & 16 & 3 \\
\hline 10 & Santa Margarita & Caudete & - & 14 & -1 & - \\
\hline 11 & Peńón Grande II & Caudete & 300 & 136 & 41 & 3 \\
\hline 12 & Lomica de la Plata I & Caudete & 300 & 122 & 25 & 3 \\
\hline 13 & Lomica de la Plata II & Caudete & 300 & 111 & 14 & 3 \\
\hline 14 & Peñón Grande I & Caudete & 150 & 302 & 193 & 3 \\
\hline 15 & $\begin{array}{l}\text { Loma de la Rambla } \\
\text { Toconera }\end{array}$ & Caudete & 150 & 57 & 10 & 3 \\
\hline 16 & El Espolón & Caudete & 300 & 100 & 29 & 3 \\
\hline 17 & La Atalaya & Caudete & 3500 & 124 & 65 & 1 \\
\hline 18 & Cerro El Rocín & Villena & 100 & 193 & 123 & 3 \\
\hline 19 & Cerro de las Albarizas & Villena & 300 & 49 & 23 & 3 \\
\hline 20 & $\begin{array}{l}\text { Alto del Barranco del } \\
\text { Infierno }\end{array}$ & Villena & 50 & 140 & 58 & 3 \\
\hline 21 & Cerro del Cantalar & Villena & 300 & 52 & 22 & 3 \\
\hline 22 & \begin{tabular}{|l} 
Peñón de los Cuervos \\
n. 2
\end{tabular} & Villena & 500 & 132 & 20 & 3 \\
\hline 23 & $\begin{array}{l}\text { Peñón de los Cuervos } \\
\text { n. }{ }^{0} 1\end{array}$ & Villena & 300 & 170 & 57 & 3 \\
\hline 24 & Altos de la Zafra & Villena & 300 & 235 & 99 & 3 \\
\hline 25 & El Castellar & Villena & 50 & 119 & 58 & 3 \\
\hline 26 & Cerro de la Hiedra & \begin{tabular}{|l|} 
Villena \\
\end{tabular} & 300 & 45 & 10 & 3 \\
\hline 27 & Cerro de la Escoba & \begin{tabular}{|l|} 
Villena \\
\end{tabular} & 3500 & 118 & 59 & 1 \\
\hline 28 & Cabezos de Penalva 2 & \begin{tabular}{|l|} 
Villena \\
\end{tabular} & 200 & 49 & 30 & 3 \\
\hline 29 & Cabezos de Penalva I & \begin{tabular}{|l|} 
Villena \\
\end{tabular} & 450 & 50 & 29 & 3 \\
\hline 30 & Cabezo de la Virgen 2 & \begin{tabular}{|l|} 
Villena \\
\end{tabular} & 357 & 100 & 69 & 3 \\
\hline 31 & Cabezo de la Virgen 1 & \begin{tabular}{|l|} 
Villena \\
\end{tabular} & 3000 & 192 & 154 & 1 \\
\hline 32 & Cabezo del Molinico & \begin{tabular}{|l|} 
Villena \\
\end{tabular} & 1680 & 32 & 19 & 2 \\
\hline 33 & Cabezo Redondo & Villena & 6000 & 66 & 47 & 1 \\
\hline 34 & Peńón de la Zorra & Villena & 500 & 126 & 38 & 3 \\
\hline 35 & Los Pedruscales & \begin{tabular}{|l|} 
Villena \\
\end{tabular} & 50 & 90 & -2 & 3 \\
\hline 36 & \begin{tabular}{|l}
$\begin{array}{l}\text { Peñón de los } \\
\text { Mosquitos }\end{array}$ \\
\end{tabular} & Villena & 400 & 84 & 39 & 3 \\
\hline 37 & Terlinques & \begin{tabular}{|l|} 
Villena \\
\end{tabular} & 1600 & 91 & 63 & 2 \\
\hline 38 & $\begin{array}{l}\text { Cabezo del Polovar } \\
\text { occidental }\end{array}$ & Villena & 100 & 78 & 69 & 3 \\
\hline 39 & $\begin{array}{l}\text { Cabezo del Polovar } \\
\text { central }\end{array}$ & Villena & 100 & 80 & 71 & 3 \\
\hline 40 & \begin{tabular}{|l|} 
Cabezo del Polovar \\
oriental
\end{tabular} & Villena & 100 & 75 & 66 & 3 \\
\hline 41 & Castillo de la Atalaya & Villena & - & 53 & 21 & - \\
\hline
\end{tabular}

\begin{tabular}{|c|c|c|c|c|c|c|}
\hline N. ${ }^{\circ}$ & YACIMIENTO & Municipio & $\begin{array}{c}\text { TAMAŃO } \\
\left(\mathrm{m}^{2}\right)\end{array}$ & $\begin{array}{l}\mathrm{H}_{\mathrm{R}} \\
(\mathrm{m})\end{array}$ & $\begin{array}{l}\mathrm{H}_{\mathrm{R}} \\
(\mathrm{m})\end{array}$ & Grupo \\
\hline 42 & Castillo de Salvatierra & Villena & - & 220 & 135 & - \\
\hline 43 & Las Peñicas & Villena & 410 & 161 & 76 & 3 \\
\hline 44 & Barranco Tuerto & \begin{tabular}{|l|} 
Villena \\
\end{tabular} & 90 & 177 & 69 & 3 \\
\hline 45 & Cabezo de Valera 2 & \begin{tabular}{|l|} 
Villena \\
\end{tabular} & 150 & 81 & 23 & 3 \\
\hline 46 & Cabezo de Valera 1 & Villena & 1500 & 125 & 48 & 2 \\
\hline 47 & Sierra del Collado I & \begin{tabular}{|l|} 
Villena \\
\end{tabular} & 130 & 224 & 132 & 3 \\
\hline 48 & Cabezo de las Torbas 1 & \begin{tabular}{|l|} 
Villena \\
\end{tabular} & 30 & 82 & 28 & 3 \\
\hline 49 & Cabezo de las Torbas 2 & \begin{tabular}{|l|} 
Villena \\
\end{tabular} & 1500 & 79 & 37 & 2 \\
\hline 50 & Peñón del Rey & Villena & 450 & 180 & 99 & 3 \\
\hline 51 & Peńón de la Moneda & Villena & 200 & 287 & 207 & 3 \\
\hline 52 & $\begin{array}{l}\text { La Fontanella o La } \\
\text { Blasca }\end{array}$ & Banyeres & 300 & 277 & 141 & 3 \\
\hline 53 & El Bovar o L'Hedra & Banyeres & 132 & 70 & 1 & 3 \\
\hline 54 & La Serrella 2 & Banyeres & 150 & 134 & 44 & 3 \\
\hline 55 & La Serrella 1 & Banyeres & 2000 & 148 & 46 & 2 \\
\hline 56 & Alt de la Crehueta & Banyeres & 300 & 230 & 119 & 3 \\
\hline 57 & Cabeço dels Llorenços & Banyeres & 300 & 144 & 55 & 3 \\
\hline 58 & El Blanquinal I & Beneixama & 200 & 124 & 38 & 3 \\
\hline 59 & El Blanquinal II & Beneixama & 376 & 281 & 120 & 3 \\
\hline 60 & El Blanquinal III & Beneixama & 200 & 211 & 29 & 3 \\
\hline 61 & Cerro de los Purgaticos & La Canyada & 60 & 85 & 28 & 3 \\
\hline 62 & Cabezo Candela & La Canyada & 168 & 69 & 37 & 3 \\
\hline 63 & La Crehueta & La Canyada & 1980 & 110 & 72 & 2 \\
\hline 64 & La Mina & La Canyada & 1300 & 105 & 73 & 2 \\
\hline 65 & Castell d'Almirra & Camp de Mirra & - & 116 & 83 & - \\
\hline 66 & La Fantasmeta & Camp de Mirra & 594 & 96 & 67 & 3 \\
\hline 67 & Castell de Biar & Biar & - & 128 & 67 & - \\
\hline 68 & Les Fontanelles II & Biar & 402 & 132 & 26 & 3 \\
\hline 69 & Les Fontanelles I & Biar & 538 & 140 & 31 & 3 \\
\hline 70 & Cabezo Gordo II & Biar & 180 & 366 & 187 & 3 \\
\hline 71 & El Picacho I & Biar & 185 & 207 & 60 & 3 \\
\hline 72 & El Picacho II & Biar & 150 & 231 & 66 & 3 \\
\hline 73 & El Picacho IV & Biar & 150 & 185 & 10 & 3 \\
\hline 74 & Cantal de Ferris II & Biar & 200 & 105 & -16 & 3 \\
\hline 75 & Penya Buitrera & Biar & 140 & 351 & 133 & 3 \\
\hline 76 & Cabeço de les Gerres & Biar & 237 & 106 & 54 & 3 \\
\hline 77 & Cantal de Ferris I & Biar & 137 & 167 & 29 & 3 \\
\hline 78 & El Puntal & Sax & 300 & 168 & 65 & 3 \\
\hline 79 & $\begin{array}{l}\text { Cabeç del Frare } \\
\text { Quinto }\end{array}$ & Onil & 500 & 150 & -9 & 3 \\
\hline 80 & El Tormo & Onil & 200 & 217 & 32 & 3 \\
\hline 81 & Alt de la Paella & Castalla & 150 & 263 & 131 & 3 \\
\hline 82 & Castell de Castalla & Castalla & - & 134 & 92 & - \\
\hline 83 & Cap Fontès & Castalla & 200 & 77 & 22 & 3 \\
\hline 84 & Cabeç dels Campellos & Castalla & 560 & 103 & 47 & 3 \\
\hline 85 & Foia de la Perera & Castalla & 360 & 53 & 7 & 3 \\
\hline 86 & Doncelleta del Barber & Ibi & 400 & 58 & -14 & 3 \\
\hline 87 & Fernova & Ibi & 300 & 115 & 49 & 3 \\
\hline 88 & Ermita de San Miguel & Ibi & - & 99 & 34 & - \\
\hline
\end{tabular}

FIG. 3. Relación de yacimientos arqueológicos en el territorio de estudio, indicando su extensión superficial, altura relativa sobre el llano y la propuesta de agrupación en la que se incluirían. 


\begin{tabular}{|c|c|c|c|c|c|c|}
\hline N. ${ }^{\circ}$ & Yacimiento & Municipio & $\begin{array}{l}\text { TAMAŃO } \\
\left(\mathrm{m}^{2}\right)\end{array}$ & $\begin{array}{l}\mathrm{H}_{\mathrm{RI}} \\
(\mathrm{m})\end{array}$ & $\begin{array}{l}\mathrm{H}_{\mathrm{k} 2} \\
(\mathrm{~m})\end{array}$ & Grupo \\
\hline 89 & Castell Vermell & Ibi & - & 107 & 45 & \\
\hline 90 & Castell Vell & $\mathrm{Ibi}$ & - & 152 & 19 & \\
\hline 91 & La Cascada & $\mathrm{Ibi}$ & 500 & 147 & -5 & 3 \\
\hline 92 & Santa María & $\mathrm{Ibi}$ & 500 & 147 & -3 & 2 \\
\hline 93 & Els Pans dels Moros & Ibi & 300 & 100 & -11 & 3 \\
\hline 94 & Mas del Canonge & Alcoi & 300 & 186 & 9 & 3 \\
\hline 95 & $\begin{array}{l}\text { Clapissa del Mas de } \\
\text { Romà }\end{array}$ & Alcoi & 300 & 205 & 20 & 3 \\
\hline 96 & $\begin{array}{l}\text { Tossal del Barranc de } \\
\text { la Batalla } \\
\end{array}$ & Alcoi & 150 & 182 & 36 & 3 \\
\hline 97 & \begin{tabular}{|l|} 
Alt de la Penya del \\
Comptador
\end{tabular} & Alcoi & 150 & 172 & 63 & 3 \\
\hline 98 & $\begin{array}{l}\text { Cornisa del Abric } 3 \text { de } \\
\text { La Sarga }\end{array}$ & Alcoi & 100 & 113 & 21 & 3 \\
\hline 99 & Els Plans del Mig & Alcoi & 300 & 137 & 25 & 3 \\
\hline 100 & Lloma del Taularet & Tibi & - & 100 & 13 & - \\
\hline 101 & \begin{tabular}{|l|} 
Cabeço de la \\
Torrosella \\
\end{tabular} & Tibi & 25 & 92 & 13 & 3 \\
\hline 102 & $\begin{array}{l}\text { Cabeço del Pinar } \\
\text { del Pla } \\
\end{array}$ & Tibi & 300 & 60 & 1 & 3 \\
\hline 103 & El Cantalar & Tibi & 100 & 125 & 55 & 3 \\
\hline 104 & $\begin{array}{l}\text { Cabeço del Ull de } \\
\text { la Font }\end{array}$ & Tibi & - & 146 & 14 & - \\
\hline 105 & Castell de Tibi & Tibi & - & 150 & 52 & - \\
\hline 106 & Cerro de la Cresta & \begin{tabular}{|l|} 
Tibi \\
\end{tabular} & 300 & 181 & 66 & 3 \\
\hline 107 & La Font Vella & Xixona & 1000 & 60 & -30 & 2 \\
\hline 108 & \begin{tabular}{|l|} 
El Tossal de les \\
Mamelludes \\
\end{tabular} & Xixona & 150 & 74 & -32 & 3 \\
\hline 109 & $\begin{array}{l}\text { Cerro Casa de Don } \\
\text { Pedro }\end{array}$ & Salinas & 1000 & 103 & 18 & 1 \\
\hline 110 & Castell de Petrer & Petrer & - & 88 & 26 & - \\
\hline 111 & Puntal del Ginebre & Petrer & 200 & 285 & 116 & 3 \\
\hline 112 & Alt del Perrió & Petrer & 300 & 136 & 17 & 3 \\
\hline 113 & Mirabuenos & Petrer & 300 & 223 & 108 & 3 \\
\hline 114 & Catí-Foradà & Petrer & 2000 & 240 & 118 & 2 \\
\hline 115 & Peñón del Trinitario & Elda & 500 & 135 & 47 & 3 \\
\hline 116 & El Monastil & Elda & - & 73 & 22 & - \\
\hline 117 & Pont de la Jaud & Elda & 500 & 104 & 62 & 3 \\
\hline 118 & Sambo Mayor & Novelda & - & 177 & 131 & - \\
\hline
\end{tabular}

\begin{tabular}{|c|c|c|c|c|c|c|}
\hline N. ${ }^{\circ}$ & YaCimiento & Municipio & $\begin{array}{c}\text { TAMAŃO } \\
\left(\mathrm{m}^{2}\right)\end{array}$ & $\begin{array}{l}\mathrm{H}_{\mathrm{RI}} \\
(\mathrm{m})\end{array}$ & $\begin{array}{l}\mathrm{H}_{\mathrm{R} 2} \\
(\mathrm{~m})\end{array}$ & Grupo \\
\hline 119 & La Llometa & Monóvar & 1000 & 127 & 67 & 2 \\
\hline 120 & Peña de la Zafra & Monóvar & 150 & 288 & 178 & 3 \\
\hline 121 & Sambo Menor & Novelda & 100 & 50 & 2 & 3 \\
\hline 122 & Casa Romà & Novelda & 300 & 42 & 3 & 3 \\
\hline 123 & Puntal de Bartolo & Novelda & 300 & 179 & 110 & 3 \\
\hline 124 & Castillo de la Mola & Novelda & - & 84 & 27 & - \\
\hline 125 & La Esparraguera & Novelda & 1300 & 84 & 18 & 2 \\
\hline 126 & Montagut I & Novelda & 100 & 259 & 185 & 3 \\
\hline 127 & Montagut II & Novelda & 200 & 210 & 136 & 3 \\
\hline 128 & Casa Paus & Novelda & 300 & 69 & 25 & 3 \\
\hline 129 & El Castillarejo & Pinoso & 400 & 222 & 130 & 3 \\
\hline 130 & El Calafuch & Monóvar & 400 & 69 & 41 & 3 \\
\hline 131 & El Ramblizo & $\begin{array}{l}\text { Hondón de las } \\
\text { Nieves }\end{array}$ & 400 & 116 & 38 & 3 \\
\hline 132 & La Horna & Aspe & 1000 & 153 & 84 & 2 \\
\hline 133 & La Mesa de Piedra & Aspe & 600 & 108 & 64 & 3 \\
\hline 134 & Las Tres Hermanas & Aspe & - & 151 & 94 & - \\
\hline 135 & El Azud & $\begin{array}{l}\text { Monforte del } \\
\text { Cid }\end{array}$ & 300 & 20 & 5 & 3 \\
\hline 136 & Lloma Redona & $\begin{array}{l}\text { Monforte del } \\
\text { Cid }\end{array}$ & 300 & 113 & 73 & 3 \\
\hline 137 & El Portitxol & \begin{tabular}{|l} 
Monforte del \\
Cid \\
\end{tabular} & 3000 & 103 & 62 & 1 \\
\hline 138 & Carochita & Torremanzanas & - & 208 & 65 & - \\
\hline 139 & Abió & Xixona & 520 & 190 & 65 & 3 \\
\hline 140 & Els Arrendadors & Torremanzanas & 100 & 151 & 34 & 3 \\
\hline 141 & Castellet de la Murta & Agost & - & 224 & 129 & - \\
\hline 142 & El Negret & Agost & 3440 & 80 & 54 & 1 \\
\hline 143 & El Pinchillet & Agost & 242 & 77 & 52 & 3 \\
\hline 144 & Cerro de los Lobos & Alicante & 976 & 127 & 95 & 2 \\
\hline 145 & Cerro Venta Amaro & Mutxamel & 55 & 75 & 37 & 3 \\
\hline 146 & Serra Bonalba & Mutxamel & 384 & 114 & 59 & 3 \\
\hline 147 & Les Canyades & El Campello & 300 & 87 & -2 & 3 \\
\hline 148 & Loma del Garbinet & Alicante & 280 & 88 & 56 & 3 \\
\hline 149 & Serra Grossa & Alicante & 248 & 110 & 69 & 3 \\
\hline 150 & $\begin{array}{l}\text { Benacantil-Arrabal } \\
\text { Roig } \\
\end{array}$ & Alicante & - & 90 & 51 & - \\
\hline 151 & $\begin{array}{l}\text { Benacantil-Cara del } \\
\text { Moro }\end{array}$ & Alicante & - & 150 & 117 & - \\
\hline
\end{tabular}

FIG. 3. Relación de yacimientos arqueológicos en el territorio de estudio, indicando su extensión superficial, altura relativa sobre el llano y la propuesta de agrupación en la que se incluirian (continuación).

hasta su abandono en torno a $1250 \mathrm{cal} \mathrm{AC}$, la mayor parte de su trama urbanística y dataciones corresponden a la fase del Bronce Tardío, con enterramientos individuales dentro del área de hábitat (Hernández et al., 2016). Ningún otro de los yacimientos documentados en este amplio espacio físico muestra una secuencia de ocupación tan amplia, ni alcanza una magnitud comparable.
Los 151 yacimientos conocidos se reparten de forma desigual por el territorio en estudio. La mayor densidad se detecta en el curso alto del Vinalopó y la cubeta de Villena, en donde se documenta un total de 75 . Ello supone que casi el 50\% de los yacimientos se localiza en una superficie próxima a los $785 \mathrm{~km}^{2}$. Probablemente, las óptimas condiciones edáficas y la riqueza biológica e hídrica de 


\begin{tabular}{|c|c|c|c|c|}
\hline ZonA & Superficie & $\begin{array}{c}\text { N. }{ }^{\circ} \\
\text { YACIMIENTOS }\end{array}$ & Densidad & $\begin{array}{l}\text { DISTANCIA ENTRE } \\
\text { YACIMIENTOS }\end{array}$ \\
\hline Alto Vinalopó & $785,59 \mathrm{~km}^{2}$ & 75 & $\begin{array}{c}1 \text { yacimiento / } \\
10,47 \mathrm{~km}^{2}\end{array}$ & $1,17 \mathrm{~km}$ \\
\hline Alto Montnegre & $380,69 \mathrm{~km}^{2}$ & 34 & $\begin{array}{c}1 \text { yacimiento / } \\
11,20 \mathrm{~km}^{2}\end{array}$ & $1,28 \mathrm{~km}$ \\
\hline Medio Vinalopó & $892,08 \mathrm{~km}^{2}$ & 28 & $\begin{array}{c}1 \text { yacimiento / } \\
31,86 \mathrm{~km}^{2}\end{array}$ & $2,78 \mathrm{~km}$ \\
\hline Bajo Montnegre & $661,93 \mathrm{~km}^{2}$ & 14 & $\begin{array}{c}1 \text { yacimiento / } \\
47,28 \mathrm{~km}^{2}\end{array}$ & $3,15 \mathrm{~km}$ \\
\hline TотаL & $2720,29 \mathrm{~km}^{2}$ & 151 & $\begin{array}{c}\text { yacimiento / } \\
18,02 \mathrm{~km}^{2} \\
\end{array}$ & $1,61 \mathrm{~km}$ \\
\hline
\end{tabular}

En estas diferencias creemos que pueden influir, entre otros, factores de carácter político vinculados al establecimiento de la frontera argárica (López Padilla, 2011: 103), aunque también se debe tener en cuenta el diferente grado de intensidad en la prospección territorial efectuada hasta la fecha.

La extensión superficial con-

FIG. 4. Comparación entre la superficie territorial, número de yacimientos, densidad $y$ distancia entre yacimientos por comarcas naturales en el área de estudio. servada es uno de los datos de mayor interés para concretar esta zona del Alto Vinalopó contribuyen a explicar esta mayor densidad. En cualquier caso, los datos permiten proponer una extensión del hábitat de 1 yacimiento cada $10-11 \mathrm{~km}^{2}$ en esta zona, densidad similar a la del curso alto del río Montnegre. Esta alta concentración contrasta con lo registrado en los cursos medio y bajo de estos ríos, donde la relación es casi tres o cuatro veces superior respectivamente y la distancia entre yacimientos se duplica (Fig. 4). la magnitud de los yacimientos. Dejando de lado aquellos donde la presencia de ocupaciones humanas posteriores, básicamente de época medieval -pero también durante el Bronce Tardío en el caso de Cabezo Redondo, El Negret y Portixol-, ha alterado su fisionomía de forma irrecuperable, impidiendo realizar estimaciones sobre su tamaño original -unos 22 yacimientos y el $14,57 \%$ del total-, los datos obtenidos muestran que apenas algo

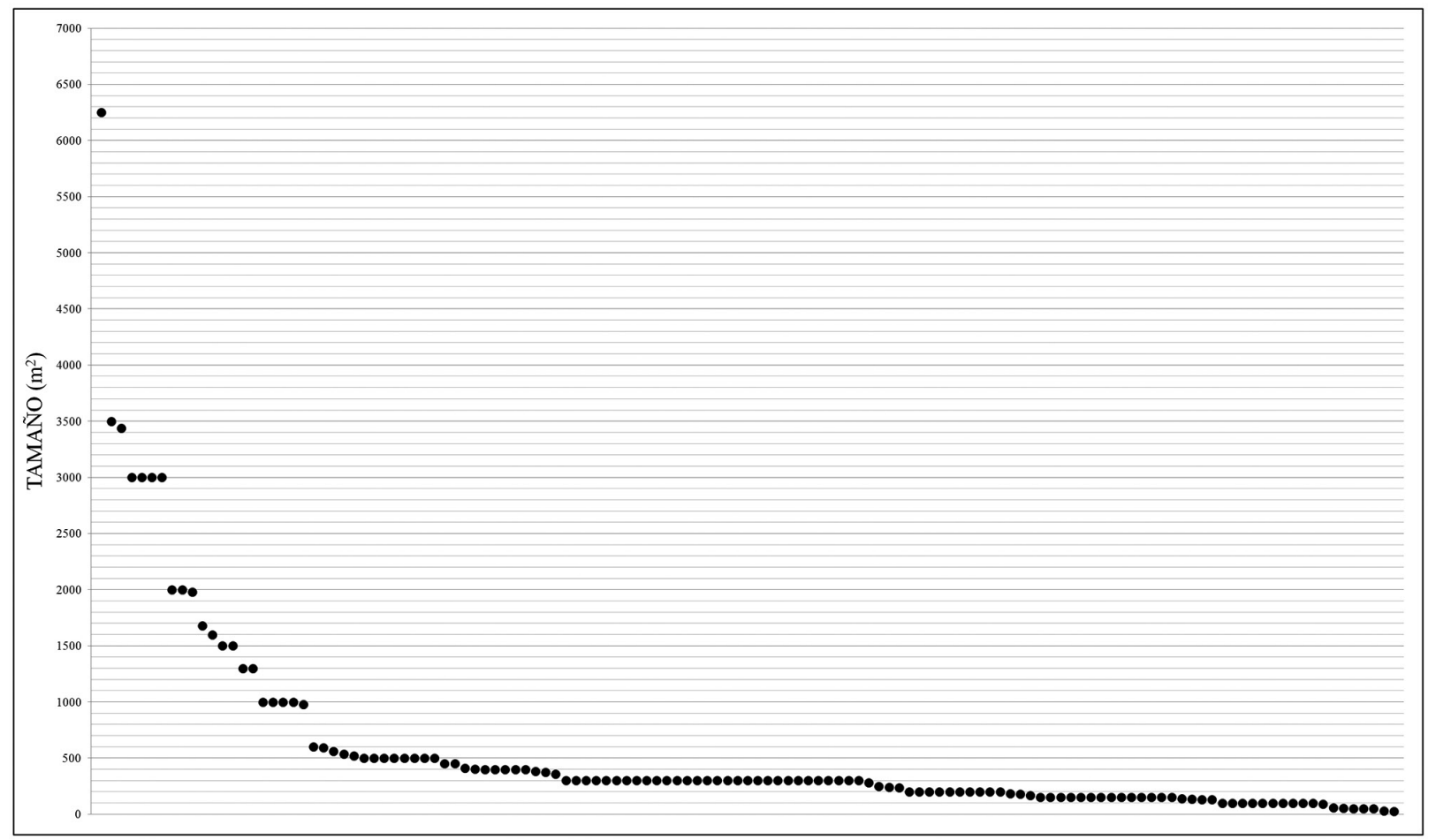

FIG. 5. Gráfica donde se muestra la distribución general del tamaño de los asentamientos en estudio en $m^{2}$. 
más del $15 \%$ podría corresponderse con los asentamientos de mayor tamaño en la escala regional -entre 0,1 y 0,35 ha-, mientras que el $85 \%$ restante serían núcleos con una extensión inferior a las 0,06 ha, de los cuales más del $60 \%$ son inferiores a 300 $\mathrm{m}^{2}$. Entre los núcleos de mayor tamaño, parece evidente que solo unos pocos -únicamente $6^{8}$ de 19podrían haber alcanzado una extensión entre 3.000 y $3.500 \mathrm{~m}^{2}$. De ellos, 4 -Cabezo de la Escoba, Cabezo del Rosario, la Atalaya y Cabezo de la Virgen 1- se ubican en la cubeta de Villena, justamente donde se localiza Cabezo Redondo y una de las zonas más fértiles edáfica y biológicamente del área en estudio (Fig. 5). Estos datos son equiparables a los constatados en otras cuencas levantinas más septentrionales (Palomar, 1995; Ribera y Pascual, 1997; García Borja, 2004; De Pedro et al., 2015).

Por otro lado, un análisis de su distribución muestra la presencia recurrente de agrupaciones de asentamientos -normalmente 3 o 4-ubicados de forma muy próxima unos de otros, cuestión que ya fue señalada a través de la aplicación de técnicas como la del coeficiente del vecino más próximo para la cubeta de Villena (Jover y López, 1999) y el curso bajo del río Montnegre (Soriano, 2004). Por lo general, en esas agrupaciones suele documentarse algún núcleo de mayor tamaño que el resto.

En otro sentido, la altura relativa de los yacimientos sobre su territorio más próximo varía notablemente en función de las condiciones topográficas de cada zona. No obstante, hay un patrón bastante significativo que constatamos de forma recurrente. La mayor parte de los yacimientos ocupan cerros aislados en medio del llano o promontorios rocosos adelantados ubicados en estribaciones montañosas que les confieren una posición ligeramente

8 De los 6 yacimientos, en 3 de ellos está atestiguada una amplia ocupación durante el Bronce Tardío -Portixol, El Negret (Barciela et al., 2012) - o de momentos del Bronce final y del Hierro Antiguo -Cabezo de la Virgen 1-, lo que impide considerar de forma fehaciente que su tamaño durante las fases previas pudiese corresponderse con el determinado a nivel superficial. De igual modo, el yacimiento de la Esparraguera (Navarro, 1982), de unos $1.300 \mathrm{~m}^{2}$, también cuenta con vasijas de clara adscripción al Bronce Tardío/Final I. sobreelevada sobre su entorno circundante, aunque en el caso del curso alto del río Montnegre muchos de estos enclaves, a pesar de encontrarse en altura, no presentan una posición destacada sobre su entorno (Fig. 6). Estas características son las que presentan buena parte de los enclaves de mayores dimensiones de este territorio, pero también buena parte de aquellos de tamaño más reducido. Sin embargo, un significativo número de yacimientos -el $25 \%$-, en su mayor parte inferiores a $300 \mathrm{~m}^{2}$ con excepción del Cabezo de la Virgen 1 y Catí-Foradà, ocupa cerros o crestas montañosas con fuertes pendientes, aunque en ocasiones la topografía agreste en la que se emplazan y el no estar localizados en los puntos más elevados de dicho territorio implica que no destaquen por su altura relativa con respecto a la media de su entorno, distinguiéndose claramente de otros yacimientos que destacan por su posición predominante - p. e. Penya Buitrera, Peńón de la Moneda, Puntal de Ginebre (Fig. 7в) о Peña de la Zafra-. No obstante, en ambos casos, la elección de este tipo de enclaves conlleva un significativo alejamiento de cursos de agua permanentes y de tierras con mínimas condiciones edáficas para el desarrollo de prácticas agrícolas. Pero, por otro lado, facilita la posibilidad de establecer una destacada red de intervisibilidad que se extiende más allá del valle en el que se enclavan.

\section{Las excavaciones arqueológicas: hacia una caracterización de las unidades de asentamiento del Bronce Valenciano}

A la valoración de aspectos como el tamaño de los asentamientos y la altura relativa sobre el medio circundante, conviene ahora añadir la información proporcionada por las excavaciones realizadas en las últimas décadas. De algunos de los asentamientos superiores a los $1.000 \mathrm{~m}^{2}$ se cuenta con información relevante. Así, las únicas actuaciones arqueológicas efectuadas en asentamientos superiores a $3.000 \mathrm{~m}^{2}$ han sido las emprendidas en su momento por Soler en el Cabezo de la Escoba (Cabezas, 2015) y, más recientemente, en El Negret (Barciela et al., 2012). En el primero, Soler realizó al menos 3 sondeos, en 
uno de los cuales pudo documentar parte de una vivienda con un hogar al que se asociaban diversas vasijas cerámicas, pesas de telar y restos carpológicos carbonizados. En el segundo, la excavación de cerca de $400 \mathrm{~m}^{2}$ ha deparado una dilatada continuidad en la ocupación del espacio con al menos 4 unidades habitacionales. Las dataciones obtenidas para las unidades habitacionales 2 y 3 han permitido determinar que corresponden al Bronce Tardío, aunque existen niveles previos de ocupación que podrían hacer pensar que su fundación se pudo producir en momentos previos (Barciela et al., 2012: 128).

De otros, cuyo tamaño se sitúa entre 0,1 y 0,2 ha, como, por ejemplo, Terlinques (Jover y López, 2016), pero también otros más septentrionales en el Camp del Turia, como la Lloma de Betxí (De Pedro, 1998; De Pedro y Soler, 2015), gracias a las excavaciones efectuadas se ha documentado la construcción de muros de cierre y muros de aterrazamiento que exigieron una considerable inversión de trabajo para el acondicionamiento de las cimas y laderas de los cerros. La construcción de estas infraestructuras y de otras no menos relevantes, como cisternas y depósitos para el almacenamiento de agua, registrados en los asentamientos señalados, incluso de silos como en Terlinques evidencia un firme propósito de ocupación continuada e indefinida. Todos los yacimientos de este tipo que han proporcionado dataciones radiocarbónicas-Mas del Corral, Terlinques y Lloma de Betxí- muestran largas secuencias de ocupación que, en muchos casos, se inician hacia 2200/2150 cal AC, prolongándose hasta 1500/1450 cal AC (Trelis, 1992; Jover et al., 2014; Cabezas, 2015; De Pedro y Soler, 2015). En el caso de La Horna (Hernández, 1994) la ausencia de dataciones impide concretar si se trata de un

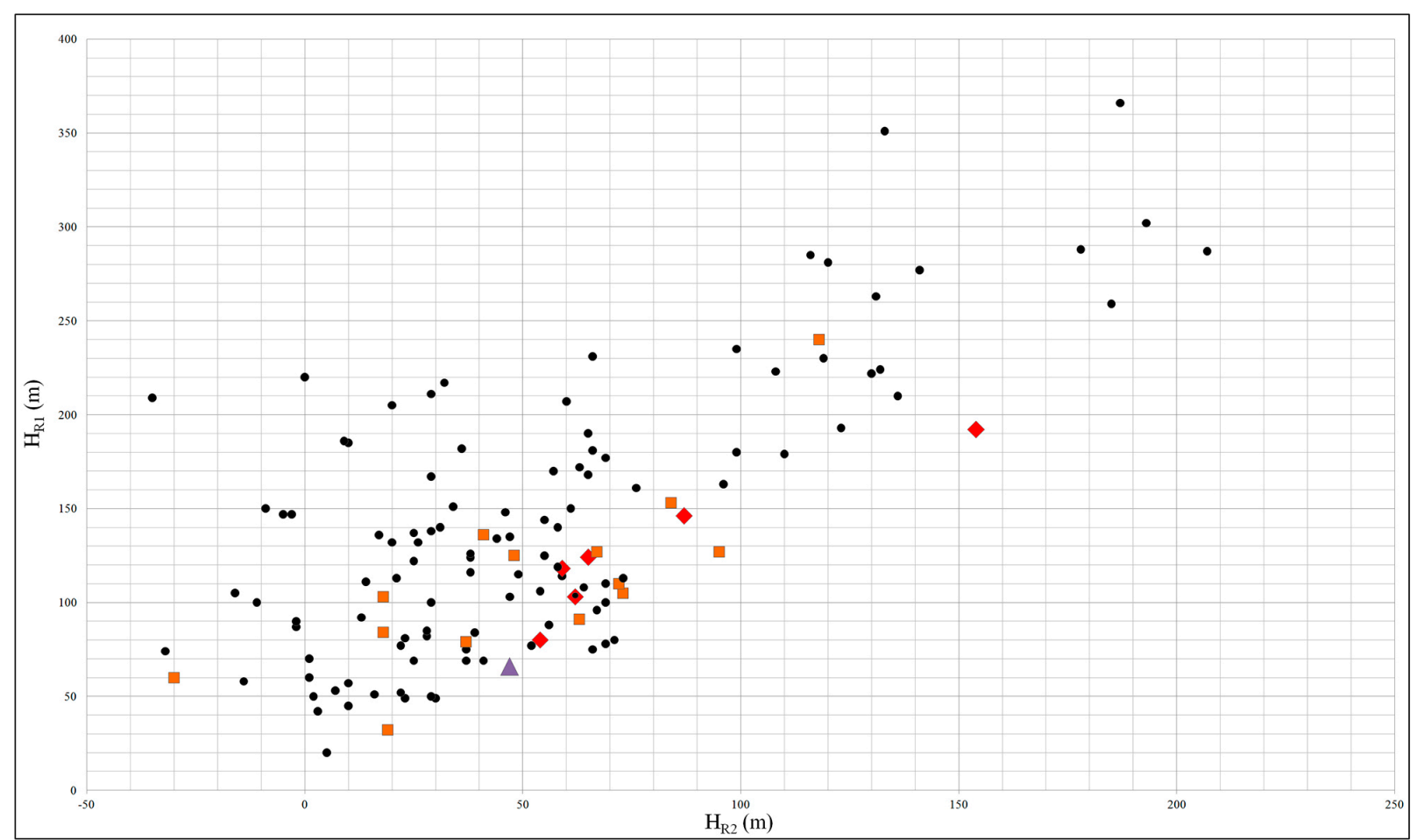

FIG. 6. Gráfica que muestra la distribución de los yacimientos estudiados relacionando la altura máxima del yacimiento y su diferencia con respecto a la altura minima $\left(H_{r}\right)$ y la altura media $\left(H_{r 2}\right)$ existente en el entorno de $1 \mathrm{~km}$. En distintos colores, simbolos y tamaños se indican las distintas agrupaciones de yacimientos consideradas en este texto a tenor de su extensión superficial. Con circulos negros los inferiores a $600 \mathrm{~m}^{2}$; con cuadrados naranjas los situados entre $1.000 y$ $2.000 \mathrm{~m}^{2}$; con rombos rojos, entre 2.000 y $3.600 \mathrm{~m}^{2}$; y con un triángulo morado, el único yacimiento superior a 6.000 $m^{2}$, Cabezo Redondo. 
yacimiento exclusivamente correspondiente a la fase del Bronce Tardío, tal y como ha sido propuesto, a partir de la tipología de sus evidencias materiales. En algunos, como Terlinques (Figs. $7 \mathrm{~d}$ y 8b), se observan importantes transformaciones en la gestión de los espacios y en la organización de las actividades productivas a lo largo de los casi 700 ańos de ocupación. Si en un primer momento resultan característicos los edificios de gran tamaño, ocasionalmente con pequeños tabiques interiores separando diversas áreas de actividad, hacia 1800/1750 cal AC se documenta una amplia transformación del espacio habitado. A partir de esos momentos, en bastantes asentamientos de este tipo se constata una planificación urbanística caracterizada por la construcción de unidades habitacionales de menor tamaño adosadas y distribuidas a ambos lados de un pasillo o calle central. En Terlinques, uno de estos edificios sobrepasaba con claridad las dimensiones del resto, concentrando en su interior, además, gran número de molinos en uso y las vasijas de mayor capacidad (Jover y López, 2016: 438). Entre el repertorio material destaca la presencia de grandes cantidades de instrumentos de molienda de distintos tamaños, así como cereales y leguminosas, vasijas cerámicas de unos $30 \mathrm{l}$ de capacidad para el almacenamiento ${ }^{9}$, todo tipo de instrumentos líticos -en especial dientes de hoz-, concentraciones de pesas de telar, fusayolas y husos, adornos de diferentes materias primas - con cierta presencia de objetos de marfil, además de una variada gama de adornos metálicos y malacológicos-, instrumentos de cobre y, en algunos casos, prácticas de fundición metalúrgica (De Pedro, 1998; Simón, 1998).

Por otro lado, y como norma general antes señalada, alrededor de estos asentamientos mayores se constata la presencia de otros de mucho menor tamańo que se agrupan en torno a ellos. Se trata de núcleos inferiores a $600 \mathrm{~m}^{2}$, aunque en su mayor parte no suelen superar los $300 \mathrm{~m}^{2}$. En su mayoría se localizan cercanos a tierras óptimas para la práctica agrícola de tipo cerealista y para el pastoreo. $\mathrm{Su}$

9 Cf. también Pérez Jordà, G. (2013): La agricultura en el País Valenciano entre el VI y el I milenio a.C. Tesis doctoral presentada en 2013 en la Universidad de Valencia (http://roderic.uv.es/handle/10550/31152). número es el más amplio en todo el territorio en estudio -el $85 \%$ de los que ha sido determinado su tamaño y el $70 \%$ de la totalidad-.

Son varios los yacimientos de este tipo excavados de los que podríamos considerar algunos datos de interés. El asentamiento de la Lloma Redona (Figs. 7c, 8c y 9c-d) (Navarro, 1986), de dimensiones inferiores a $300 \mathrm{~m}^{2}$, ocupa la parte alta de un cerro de forma cónica situado en el corredor de Agost. Se estructuraba a partir de tres líneas de muros concéntricos a modo de plataformas de aterrazamiento. En la zona más elevada, definida por su lado meridional por uno de los anillos murarios, se localizaron paredes correspondientes a dos unidades habitacionales, una de ellas expoliada. En el ambiente restante, de planta cuadrangular y unos $30 \mathrm{~m}^{2}$ de superficie (Fig. 8c), se detectó un único nivel de ocupación con un hogar, varias vasijas cerámicas -en su mayoría formas esféricas de pequeña capacidad o de uso individual- y fragmentos de molinos de pequeño tamaño, todo ello propio de un área de consumo doméstico. La única datación disponible para este asentamiento, tomada de una muestra de microcarbones, situaría su ocupación en cualquier momento de los siglos centrales de la primera mitad del II milenio cal AC (Jover et al., 2014).

En la cresta central del Cabezo del Polovar fueron documentados dos ambientes o departamentos de planta de tendencia rectangular-cuadrangular con un espacio útil próximo a $28-35 \mathrm{~m}^{2}$, con un sistema de postes que servía de sustento a la cubierta. Se hallaban separados por un muro medianero de escaso porte, en el que no pudo identificarse ningún vano que permitiera la comunicación entre ambos. Solo se ha constatado una única fase constructiva y de uso datada en los momentos centrales del in milenio cal AC. Las evidencias materiales y constructivas documentadas denotan la realización de prácticas propias de la esfera doméstica, al igual que en los yacimientos referidos anteriormente: recipientes cerámicos para el consumo y almacenamiento, junto a un silo con una capacidad para unos $25 \mathrm{~kg}$, molturación de cereales con molinos y molederas de pequeño tamaño, machacado y triturado de otras materias con percutores líticos y el consumo de ovicaprinos. 
La reciente excavación de otros núcleos de muy pequeño tamaño ha mostrado características que difieren un tanto de los anteriores, adquiriendo otras posibilidades interpretativas. Son los casos de la cresta occidental del Cabezo del Polovar y el Cerro de los Purgaticos.

La cresta occidental del Cabezo del Polovar, separada por escasamente $50 \mathrm{~m}$ de las evidencias documentadas en la cresta central, ha evidenciado la presencia de una consistente plataforma de aterrazamiento sobre la que se levantó una especie de cabaña semiabierta de solo unos $13,8 \mathrm{~m}^{2}$ de superficie construida, delimitada por un único muro en su extremo septentrional y con diversos postes de madera calzados (Fig. 8c). En este espacio, con una sola fase de ocupación, cuya finalización, a tenor de

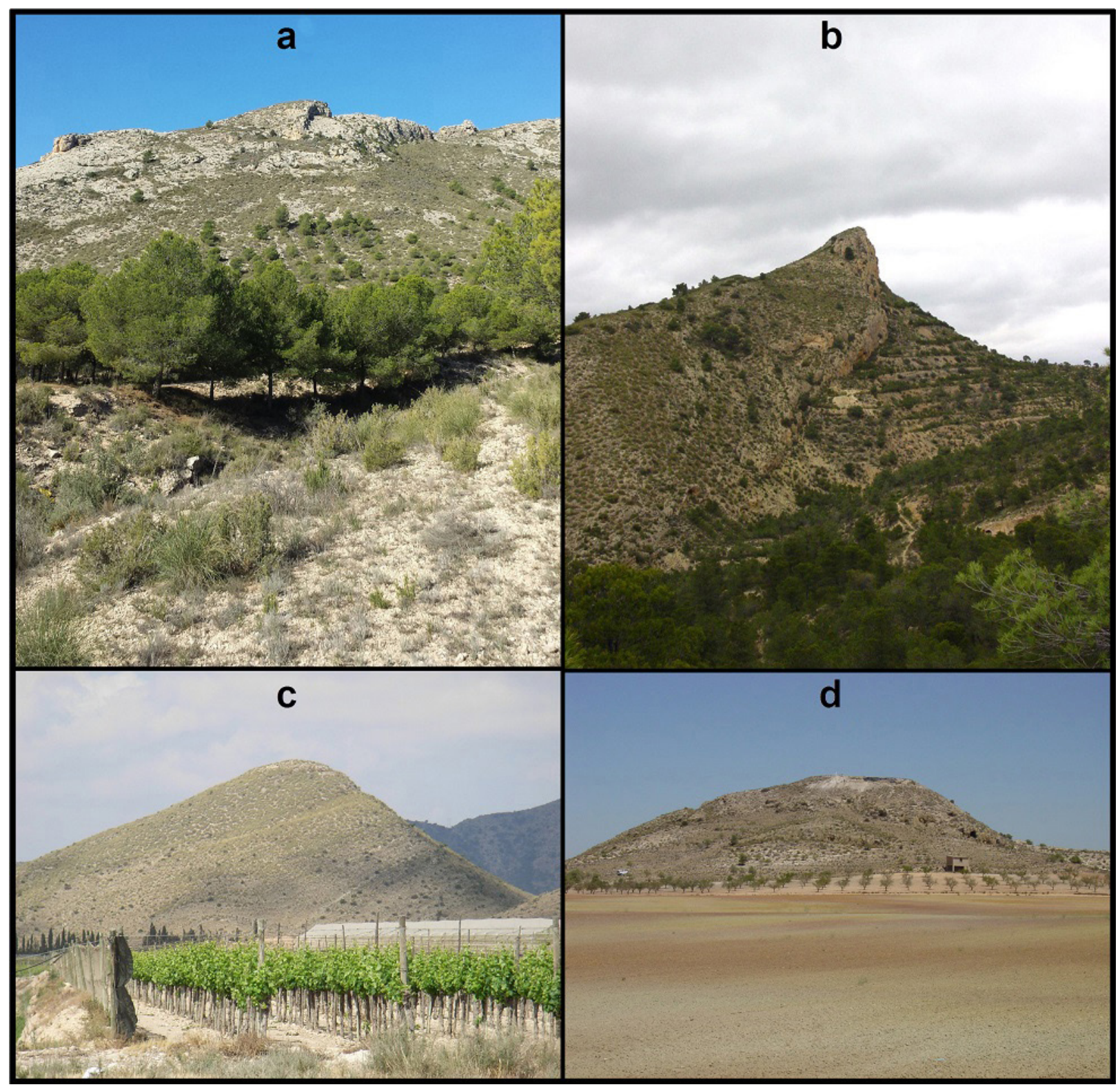

FIG. 7. Imágenes de algunos de los yacimientos destacados en el texto. Yacimientos correspondientes al Grupo 3: a) Barranco Tuerto; b) Puntal del Ginebre; c) Lloma Redona y Grupo 2: d) Terlinques. 
la datación absoluta obtenida, se situaría en torno a c. 1800 cal AC, tan solo se documentó un fragmento de saco o capazo de esparto carbonizado que contenía algunas semillas de cebada, además de escasos fragmentos cerámicos de cuencos y poco más de media docena de cuentas de collar discoidales de hueso. La gran inversión de trabajo efectuada para aterrazar dicho espacio contrasta con las reducidas dimensiones y la endeblez del edificio techado que se construyó sobre él. Además, la ausencia de hogares, silos o estructuras de combustión, así como de instrumentos de molienda, percutores, dientes de hoz o incluso de restos faunísticos, sí presentes en el resto de asentamientos señalados con anterioridad, son argumentos que han llevado a proponer que se pudiera tratar de una especie de cobertizo vinculado con un lugar de residencia próximo - ¿cresta oriental del Polovar?-, pero no con la ocupación de la cresta central, ya que cronológicamente no son coetáneos (Jover et al., 2017).

Por otro lado, el cerro de los Purgaticos es un núcleo inferior a $100 \mathrm{~m}^{2}$ caracterizado por la construcción de un gran muro plataforma adosado a la cornisa rocosa que corona el cerro, sirviendo de

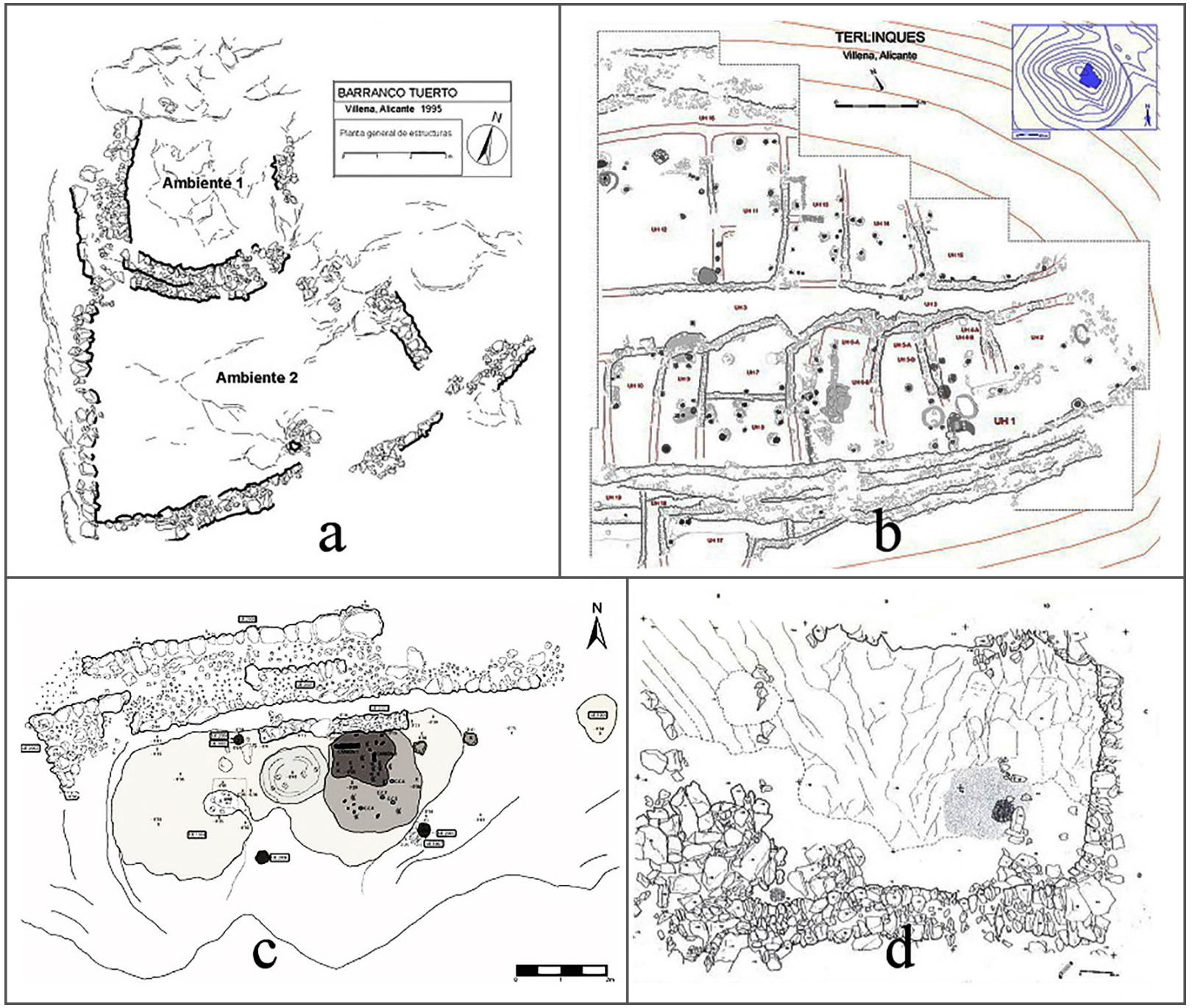

FIG. 8. Planimetría general de algunos de los yacimientos citados en el texto: a) Barranco Tuerto; b) Terlinques; c) cresta oriental del Cabezo del Polovar; d) Lloma Redonda. 
cierre de un pequeño abrigo, al que se accedía a través de un vano (Fig. 10). La constatación de un registro material centrado en ollas de boca cerrada, con la ausencia de cuencos, molinos, dientes de hoz u otros elementos que pudieran indicar la existencia de actividades de mantenimiento de un grupo humano, ha planteado la posibilidad de que pudiese tratarse de un establecimiento complementario de tipo refugio aprovechando un pequeño abrigo situado en lo alto de un cerro (Jover et al., 2017).

Por último, junto a los anteriores, ya hemos señalado la presencia de un número reducido de núcleos de muy pequeño tamaño, de no más de $300 \mathrm{~m}^{2}$ de extensión superficial en todos los casos, ubicados en puntos encumbrados de las sierras y de muy difícil acceso, lo que les confiere un importante aislamiento (Figs. 7a-b y 9a-b). No suponen más del 20\% en las cuencas de los ríos Vinalopó y Montnegre. Aunque no se puede descartar la presencia de algún pequeño punto de agua en sus proximidades, la propia elección del emplazamiento implica un considerable alejamiento, tanto de los principales cursos hídricos de la zona, como de tierras aptas para el cultivo. Hasta el momento, solo un núcleo de estas características ha sido excavado. Se trata de Barranco Tuerto (Jover y López, 1999). Su fase más antigua -la única que ha podido ser documentada dado el alto grado de erosión que ha afectado a la más reciente- destaca por la existencia de una especie de cabaña de tendencia oval de unos $18 \mathrm{~m}^{2}$, a la que se adosaba un departamento cubierto en parte, a modo de porche, de $72 \mathrm{~m}^{2}$ (Fig. 8a). No se documentaron más que vasijas cerámicas de pequeño tamaño, el ápice de una posible punta de flecha de cobre, una pesa de telar oblonga de 4 perforaciones, fragmentos de otra y restos faunísticos, predominando las extremidades de especies domésticas, y estando ausentes los instrumentos de molienda activos y los dientes de hoz y silos. La única datación disponible permite considerar que su fundación se efectuaría durante el primer cuarto del II milenio cal AC, sin que pueda confirmarse la existencia de una continuidad habitacional entre las dos fases constructivas documentadas.

En definitiva, las excavaciones efectuadas han permitido determinar que los yacimientos superiores a 0,1 ha suelen ser de larga ocupación y constituyen los principales asentamientos humanos. Por el contrario, los núcleos inferiores a $600 \mathrm{~m}^{2}$ jugaron roles muy diversos: desde asentamientos de muy reducido tamaño a establecimientos complementarios de los anteriores. Es necesario en este punto proyectar una nueva representación de las características del patrón de asentamiento y del poblamiento en las tierras meridionales del Bronce Valenciano.

\section{Hacia una representación del poblamiento en el área meridional del Bronce Valenciano}

Los datos que se han ido exponiendo a lo largo del texto evidencian que en la actualidad se cuenta con un nivel de información bastante consistente sobre las características del poblamiento durante la Edad del Bronce para algunas de las cuencas del área valenciana, en especial para las tierras meridionales. El análisis del conjunto de yacimientos efectuado permite reconocer a partir exclusivamente del tamaño de los mismos (ver Fig. 4), al menos tres agrupaciones ${ }^{10}$ para el periodo comprendido entre c. $2200 / 2150$ y $1500 / 1450 \mathrm{cal} \mathrm{AC}$.

En primer lugar, distinguimos dos conjuntos de asentamientos -Grupos 1 y 2 (Fig. 11)-, cuya extensión superficial supera los $1.000 \mathrm{~m}^{2}$, pero sin sobrepasar los $3.600 \mathrm{~m}^{2}$. Constituyen los núcleos de mayor tamaño y representan algo más del 15\%. El Grupo 1, aquellos con una extensión superficial entre 0,2 y 0,36 ha, estaría integrado por 6 asentamientos, para los que en tres casos -El Negret, Portixol y Cabezo de la Virgen 1- es imposible por el momento concretar sí realmente tendrían este tamaño en momentos previos al Bronce Tardío. Las mismas consideraciones podemos señalar para Cabezo Redondo, aunque en este caso su extensión superficial excede lo constatado para el conjunto tal

10 Sin tener en cuenta la cronología y fases de ocupación de los yacimientos, 4 serían las agrupaciones a diferenciar en función de la extensión superficial, aunque, como ya hemos indicado anteriormente, las excavaciones efectuada en Cabezo Redondo evidencian que su mayor extensión superficial la alcanzó durante los primeros siglos de la segunda mitad del II milenio cal AC, en la fase denominada Bronce Tardío. 

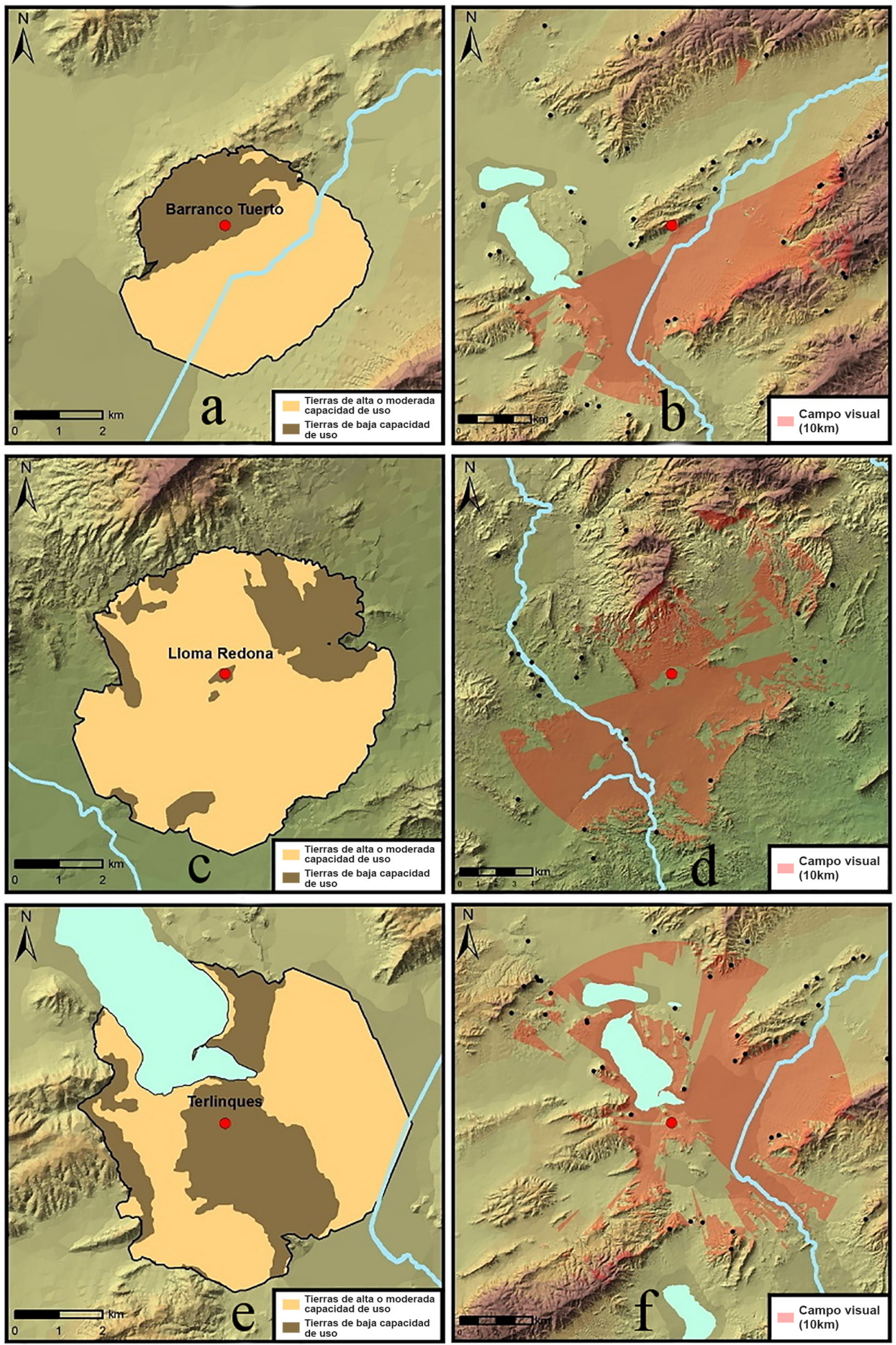

FIG. 9. Áreas de captación isocrónicas de 1 hora con indicación del potencial agrario y campo visual $(10 \mathrm{~km})$ de los yacimientos que sirven como ejemplo de cada una de las agrupaciones diferenciadas: $a$-b) Barranco Tuerto; $c$-d) Lloma Redona y e-f) Terlinques. 
y como hemos expuesto. Otros 13 asentamientos con dimensiones entre 0,1 y 0,2 ha se incluirían en el Grupo 2 ( $c f$. Fig. 4).

En cualquier caso, como muestran las dataciones disponibles de los yacimientos de ambas agrupaciones, su fundación parece remontarse a los siglos finales del III milenio cal AC y, además, presentan secuencias de ocupación prolongadas, con varias fases constructivas. En algunos de ellos se ha constatado el desarrollo de una amplia diversidad de actividades productivas -agrícolas, ganaderas, metalúrgicas, textiles, artesanales, etc.- y el consumo de determinados bienes de destacado valor social (Jover y López, 2016). Su distribución en la mayoría de los espacios geográficos analizados parece ser uniforme, y la magnitud del número de instrumentos de molienda, semillas de cereales carbonizados e incluso de silos registrados en ellos permite relacionarlos con la explotación estable de las tierras llanas ubicadas en su entorno inmediato (De Pedro, 1998; Jover, 1999; De Pedro y Soler, 2015).

Tanto en las proximidades de los asentamientos de los Grupos 1 y 2, como a una distancia considerable respecto a estos, se documenta un gran número de yacimientos -Grupo 3- de dimensiones mucho más reducidas que los anteriores -inferiores a $600 \mathrm{~m}^{2}-$. A tenor de las excavaciones efectuadas, solo una parte de ellos debieron ser núcleos de residencia en los que se llevarían a cabo las tareas necesarias para la sostenibilidad y el mantenimiento de un reducido número de personas, aunque otros, como ha sido señalado, podrían ser establecimientos de carácter logístico o complementario de los anteriores en tareas de almacenamiento, como refugio ocasional o como rediles para el ganado, entre otras actividades. Además de tener un tamaño considerablemente menor, estos enclaves se distinguen también por carecer de evidencias relacionadas con ciertas actividades productivas de carácter artesanal, sí constatadas en los asentamientos de las agrupaciones anteriores. La información secuencial de algunos de los yacimientos excavados muestra preferentemente ocupaciones monofásicas y las dataciones absolutas disponibles plantean que su fundación se pudo efectuar en cualquier momento desde finales del III milenio hasta
$1500 / 1450 \mathrm{cal} \mathrm{AC}^{11}$ - p. e., cresta occidental y cresta central del Polovar, Peńón de la Zorra (García Atiénzar, 2017), Lloma Redona, Cerro del Rocín-.

Por último, un cierto número de yacimientos de muy pequeño tamaño - menos de $300 \mathrm{~m}^{2}$-, ubicados en puntos encumbrados de las sierras, podrían constituir un subgrupo dentro del Grupo 3 (Fig. 9a-b), aunque para su correcta caracterización sería necesario contar con más información de la que ha proporcionado el único yacimiento de este tipo excavado hasta la fecha como es Barranco Tuerto (Jover y López, 1999). Con independencia de cuál fuera su función -logística, refugio ocasional, explotación silvopastoril de zonas montañosas, entre otras-, lo que parece evidente es que las óptimas condiciones que ofrecía su emplazamiento para el dominio visual del territorio se valoraron por encima de las dificultades e incomodidades que imponía lo escabroso del acceso a la gran mayoría de ellos, tanto por la altitud a la que se encontraban, como por lo abrupto y las fuertes pendientes del terreno circundante.

Por tanto, parece evidente que existieron diferencias de tamaño entre los yacimientos del área en estudio, de lo que se puede inferir una cierta disparidad en cuanto a la densidad poblacional entre los núcleos habitados. Estas mismas diferencias de tamaño han sido constatadas en las tierras orientales de La Mancha, a tenor de los resultados obtenidos en las prospecciones efectuadas (Hernández, 2002; Fernández-Posse et al., 2008). Sin embargo, los datos recabados difieren abiertamente con lo que se observa en el ámbito argárico más próximo (Martínez Monleón, 2014), donde las diferencias de tamaño entre asentamientos pueden alcanzar

11 Por el momento esta propuesta está basada en un reducido número de yacimientos excavados y datados. Otras alternativas desarrolladas en diferentes investigaciones han considerado oportuna la correlación entre los repertorios cerámicos de los contextos excavados y su extrapolación a conjuntos superficiales (Nocete, 1989: 97; Burillo y Picazo, 2001: 90-92). Sin embargo, en nuestro caso, esta posibilidad no la consideramos como viable dada la escasa variedad formal de los repertorios cerámicos documentados, tanto en los yacimientos prospectados como los excavados, además de que los repertorios obtenidos a través de prospecciones superficiales no asegura la coetaneidad de los mismos. 
valores de varias hectáreas, tanto si se trata de yacimientos localizados en el fondo de los valles cuaternarios, como en grandes cerros alejados de tierras óptimas para las prácticas agrícolas (Arteaga, 2000; Lull et al., 2011). La distinta densidad y capacidad de nuclearización poblacional de El Argar frente a los grupos culturales de su periferia septentrional es palmaria, lo que obliga a matizar y aminorar la importancia de las diferencias de tamaño constatadas en el área del Bronce Valenciano.

\section{Algunas inferencias sobre la dinámica poblacional y social de las sociedades del Bronce Valenciano}

De todo lo expuesto hasta ahora podemos inferir una serie de aspectos estrechamente vinculados con la dinámica poblacional y social subyacente al proceso histórico que conformaron las características del poblamiento de los grupos del Bronce Valenciano que acabamos de exponer:

1. Los yacimientos del Grupo 3 se revelan claramente como los más numerosos de entre los registrados en tierras valencianas, aunque habría que tener presente que una parte - por el momento difícilmente cuantificable- de los yacimientos catalogados pudieron no ser núcleos de residencia, sino más bien establecimientos complementarios para la gestión productiva del territorio ocupado. En cualquier caso, los núcleos con carácter residencial incluidos en este grupo probablemente estuvieron ocupados por un número muy reducido de personas, todas ellas involucradas en las actividades necesarias para su sostenibilidad. Estos asentamientos, como unidades mínimas de organización social, debieron de mantener necesariamente vínculos con los núcleos de mayor tamaño -Grupos 1 y $2-$, en cuyo entorno -o incluso aledaños-suelen encontrarse, no solo para obtener de ellos productos o recursos necesarios, o para afrontar con mayores garantías de supervivencia situaciones de carestía, sino, ante todo, para garantizar su reproducción a nivel biológico.
2. En los asentamientos de carácter agropecuario de mayor tamaño -tanto en el Grupo 1 como en el 2- se registran evidencias de las mismas actividades de almacenamiento, producción y consumo de bienes subsistenciales que las presentes en los asentamientos menores. En cambio, se observa en ellos una inversión de trabajo considerablemente mayor en el acondicionamiento y mantenimiento del hábitat -grandes aterrazamientos, cisternas, silos de gran capacidad-, así como la realización de ciertas actividades productivas ausentes en los núcleos menores. Sería el caso de parte de los procesos de producción textil, de manufactura de objetos de marfil y, especialmente, de la producción metalúrgica, de la que dan testimonio las escorias, lingotes, crisoles y moldes de fundición documentados hasta ahora exclusivamente en estos (Simón, 1998; Jover y López, 2016). Aunque el acceso al consumo de productos podría considerarse generalizado al conjunto de asentamientos, con independencia de su tamaño, probablemente existieron diferencias en el volumen y calidad de los objetos y materias primas foráneas a las que tuvieron acceso unos y otros y, en especial, en cuanto a las capacidades de transformación de estas últimas en artefactos.

3. Por el momento, las dataciones disponibles para los Grupos 1 y 2 plantean que la fundación de una buena parte de ellos se pudo llevar a cabo hacia finales del III milenio cal AC, perdurando hasta, al menos, mediados del milenio (Jover et al., 2014). Para los del Grupo 3, incluyendo asentamientos, pero también refugios, cobertizos o establecimientos secundarios logísticos en general, su fundación también se pudo ejecutar durante todo el periodo analizado. El surgimiento de asentamientos menores, muchos de ellos alrededor de los Grupos 1 y 2, creemos que podría ser explicado, entre otras hipótesis, como resultado de un proceso de fisión grupal desde los asentamientos mayores y de reproducción social bajo las mismas condiciones sociales y materiales, en terrenos no ocupados. Por su parte, los yacimientos de muy pequeño tamaño 


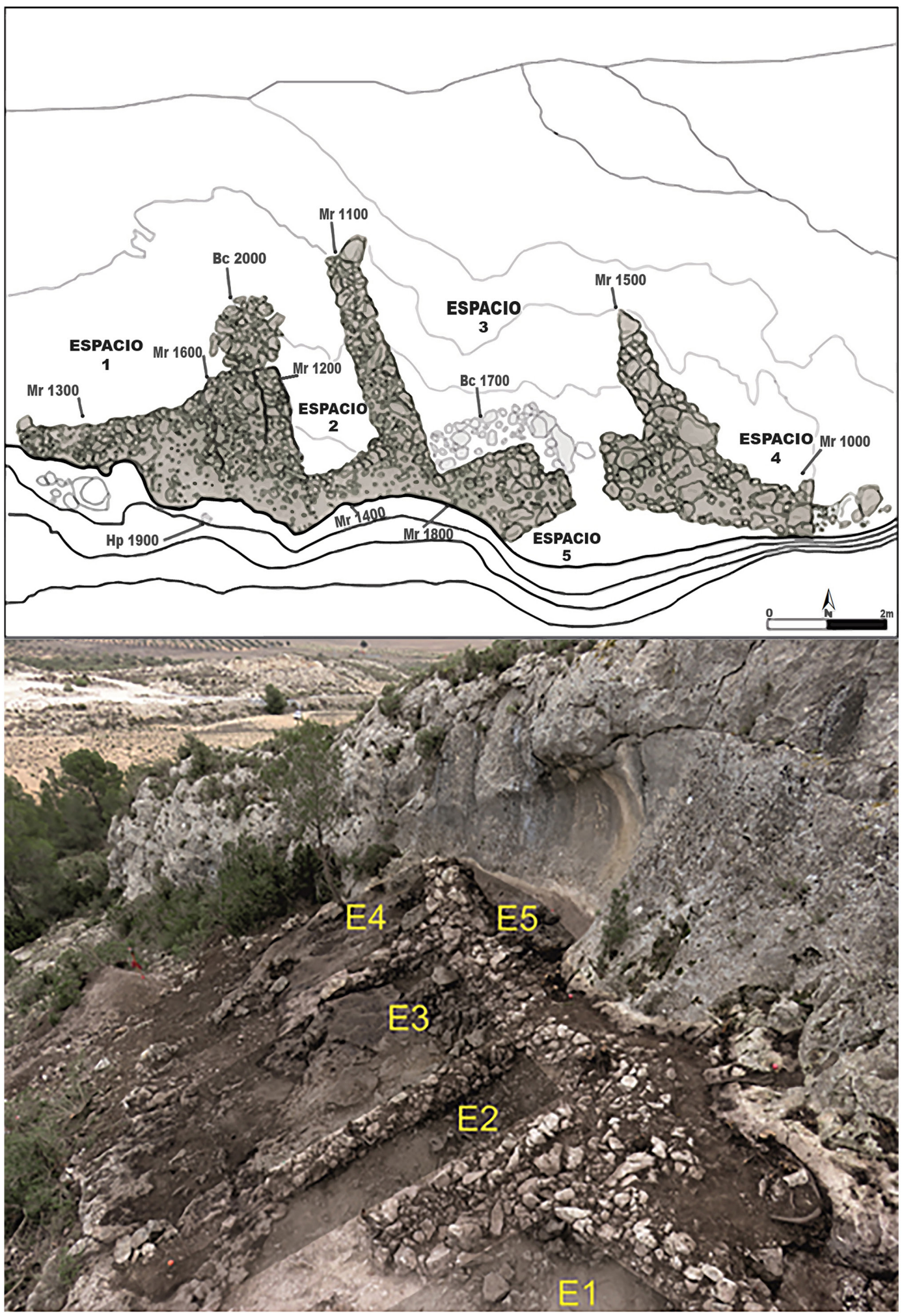

FIG. 10. Planta y visión lateral del yacimiento del Cerro de los Purgaticos. 
encumbrados podrían haber sido creados ante la necesidad de incrementar el control social sobre el espacio apropiado, respondiendo todos a una estrategia política adoptada de forma conjunta por la totalidad social. Probablemente, una parte de los asentamientos del Grupo 3, fundados ex novo, fracasarían en su intento de reproducción, dada la detección de secuencias monofásicas, mientras que otros, en cambio, se consolidarían y mantendrían activos.

4. En cualquier caso, la mayoría de los asentamientos acabarían siendo abandonados hacia 1500/1450 cal AC (Jover et al., 2014). Solo unos pocos parecen consolidarse y crecer a partir de estas fechas, caso de Cabezo Redondo (Hernández et al., 2016) o El Negret (Barciela et al., 2012), configurándose una nueva distribución poblacional, más nuclearizada, y con una mayor distancia entre asentamientos (Jover y López, 2016).

\section{Conclusiones}

En la trayectoria investigadora sobre la Edad del Bronce en las tierras valencianas se había consolidado un panorama caracterizado por la alta densidad de asentamientos de un tamaño relativamente

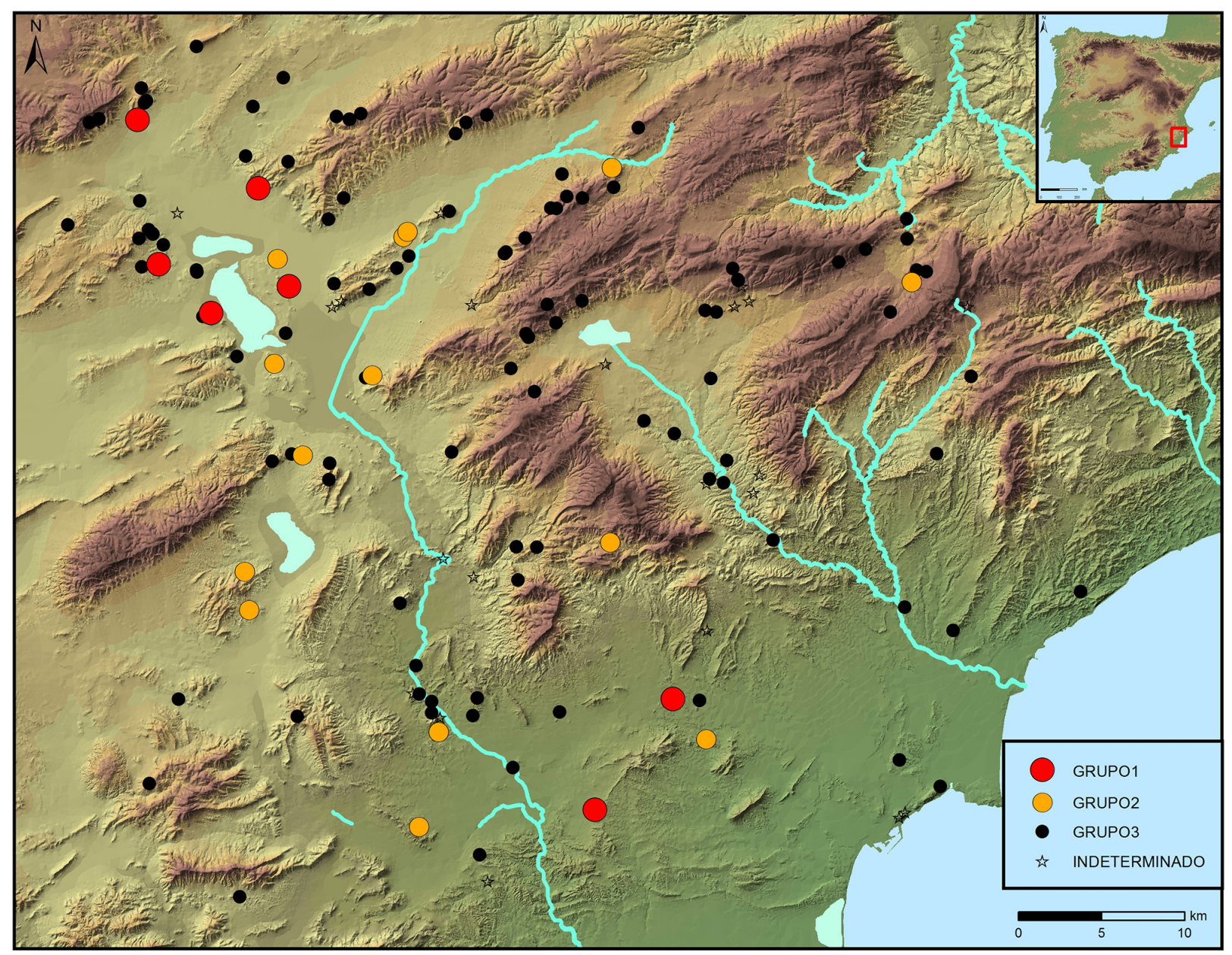

FIG. 11. Territorio específico de estudio en el que se indican las diferentes agrupaciones de yacimientos diferenciados; también se indican aquellos enormemente transformados por ocupaciones posteriores en los que es imposible determinar su tamaño $y$ demás características. 
reducido, ampliamente distribuidos en cimas, laderas de cerros y crestas adelantadas de estribaciones montañosas (Tarradell, 1963). Sin embargo, las investigaciones efectuadas en las últimas décadas vienen mostrando que la articulación poblacional fue algo más compleja que lo supuesto inicialmente (Esquembre, 1997; Ribera y Pascual, 1997; Jover y López, 1999). Los análisis territoriales unidos a la excavación y datación de un buen número de yacimientos vienen a mostrar que el registro arqueológico constatado es el resultado de la acumulación en el espacio geográfico de un conjunto de asentamientos, acompañados de establecimientos secundarios o complementarios, generados por un proyecto social iniciado c. $2200 / 2150$ cal AC y prolongado en el tiempo hasta $c .1500 / 1450 \mathrm{cal} \mathrm{AC}$, incluso $c$. $1300 / 1250 \mathrm{cal}$ AC en varios casos, del que cabe resaltar que no todos los núcleos fueron fundados al mismo tiempo. Y es que, hasta hace poco, todavía se adolecía de la falta de estratigrafías y referencias cronológicas lo bastante firmes como para posibilitar una lectura social y política de la dinámica poblacional de aquellas sociedades. Tampoco se había abordado la necesaria excavación en extensión de yacimientos de diferentes tamaños y ubicaciones.

Así, hacia c. 2200/2150 cal AC, constatamos en las tierras centrales del este de la Península Ibérica la fundación de una parte de los asentamientos adscritos en la actualidad a la Edad del Bronce. Algunos de estos núcleos ya tuvieron desde sus momentos iniciales unas dimensiones cercanas o superiores a los $1.000 \mathrm{~m}^{2}$, así como unas dilatadas secuencias de ocupación y de transformación del emplazamiento a lo largo de casi 700 ańos, como así ha sido observado en varios asentamientos excavados en extensión.

La fundación y la amplia distribución sobre el territorio de muchos de estos núcleos iniciales, con tierras susceptibles de ser explotadas en su entorno inmediato, estarían señalando el desarrollo de un nuevo proyecto político. Consecuentemente, la gestión de los espacios apropiados debió de regirse, por un lado, por la articulación de cada uno de los grupos domésticos con el medio físico, transformado o no, y, por otro, por las relaciones

(C) Universidad de Salamanca intragrupales e intergrupales que determinarían, en última instancia, tanto la distribución y asignación de las tierras y los recursos, como el modo de ejecutar las tareas y de gestionar los recursos y lo producido. Tales principios garantizarían la continuidad poblacional en los espacios asignados y refrendaría la transmisión de estos derechos de unas generaciones a otras, fortaleciendo, además, los lazos de reciprocidad intrasociales.

Además, frente a lo constatado en cuanto a prácticas funerarias en el ámbito argárico (Lull y Estévez, 1986; Lull et al., 2016), en los asentamientos del sur del Bronce Valenciano domina la inhumación múltiple en cuevas o grietas ubicadas en las proximidades de los lugares de asentamiento (McClure et al., 2010; Hernández et al., 2015). A este ritual, cabe ańadir contados enterramientos individuales, en general sin ajuares, en fosas practicadas en las terrazas o en acondicionamientos exteriores de los asentamientos (De Pedro, 2010). Tampoco se puede hablar de ajuares normalizados, predominando la ausencia de los mismos - $\mathrm{O}$, cuando excepcionalmente aparecen, como en el caso del Cabezo de la Escoba (Cabezas, 2015), hay razones para suponer una cronología relativamente avanzada para ellos-. Todo lo cual vendría a incidir en la ausencia de indicadores de estratificación social en los enterramientos, como tampoco parecen observarse en la organización territorial del poblamiento.

No obstante, tratamos con sociedades abocadas a un continuo proceso de transformación debido a su interacción constante con otras sociedades vecinas con mayor grado de desarrollo social, como es el caso de El Argar (Lull et al., 2011), con las que establecieron, a tenor del registro arqueológico, lazos productivos y reproductivos. Como resultado, durante la primera mitad del II milenio cal AC se aprecia un cierto desarrollo de las capacidades productivas y organizativas de las comunidades asentadas en buena parte del Bronce Valenciano, que pudieron derivar hacia procesos de fisión poblacional y la ocupación y puesta en explotación de nuevas tierras. De este modo, se explicaría no solo el crecimiento de muchos de los núcleos inicialmente fundados, sino también el surgimiento de buena 
parte del resto de núcleos menores en torno a los anteriores, así como enclaves o establecimientos de carácter logístico.

Así, con la intensificación de las relaciones sociales entre los grupos argáricos y las sociedades implantadas en la actual área valenciana, y ante la imposibilidad de seguir creciendo con el mismo modelo organizativo, a partir de momentos próximos a mediados del II milenio cal AC la dinámica poblacional se tuvo que reorientar políticamente -al menos en las tierras más meridionales- hacia el desarrollo de procesos de nuclearización poblacional, como el constatado en Cabezo Redondo (Hernández et al., 2016). En este sentido, no podemos olvidar que el principal elemento en los procesos productivos en este tipo de sociedades es la fuerza de trabajo humana, siendo su nuclearización uno de los cauces más directos para incrementar la capacidad productiva y propiciar mayores niveles de desigualdad social.

\section{Bibliografía}

Almagro Gorbea, M. (1997): "La Edad del Bronce en la península Ibérica: periodización y cronología", Saguntum, 30, pp. 217-229.

Antolín, C. (1998): El suelo como recurso natural en la Comunidad Valenciana. Valencia: Generalitat Valenciana.

Arteaga, O. (2000): "La sociedad clasista inicial y el origen del estado en el territorio de El Argar", Revista Atlántica-Mediterránea de Prehistoria y Arqueología Social, 3, pp. 121-219.

Ayala, M. M. (1991): El poblamiento argárico en Lorca. Estado de la cuestión. Murcia.

Barciela, V.; Hernández, M. S.; López, E. y Torregrosa, P. (2012): "A medio camino. Excavaciones arqueológicas en El Negret (Agost, Alicante)”, MARQ. Arqueología y Museos, 5, pp. 103-131.

Bernabeu, J.; Pascual, J. Ll. y Guitart, I. (1989): "Reflexiones en torno al patrón de asentamiento en el País Valenciano entre el Neolítico y la Edad del Bronce", Saguntum, 22, pp. 99-124.

Brodsky, M. C.; Gilman, A. y Martín, C. (2013): "Bronze Age Political landscapes in La Mancha". En Berrocal, M. C.; García, L. y Gilman, A. (eds.):
The Prehistory of Iberia: Debating Early Social Stratif-cation and the State. New York, pp. 141-169.

Burillo, F. (1996): "Prospección arqueológica y geoarqueología”, Arqueología Espacial, 15, pp. 67-81.

Burillo, F. y López, J. (2005/06): "Una propuesta cuantitativa de descripción de los asentamientos para un sistema de información geoarqueológica”, Kalathos, 24-25, pp. 69-84.

Burillo, F. y PeŃa, J. L. (1984): "Modificaciones por factores geomorfológicos en el tamaño y ubicación de los asentamientos primitivos", Arqueología Espacial, 1, pp. 91-105.

Burillo, F. y Picazo, J. (2001): "Prospección arqueológica y Edad del Bronce: una experiencia en la serranía turolense". En Ruiz-Gálvez, M. (coord.): La Edad del Bronce ¿Primera Edad de Oro de España? Sociedad, economía e ideología. Barcelona: Critica, pp. 87-120.

Cabezas, R. (2015): El Cabezo de la Escoba (Villena, Alicante): revisión de un asentamiento de la Edad del Bronce en el corredor del Vinalopó. Villena: Fund. José María Soler.

Cámara, J. A.; Contreras, F.; Lizcano, R.; Pérez, C.; Salas, F. E. y Spanedda, L. (2007): "Patrón de asentamiento y control de los recursos en el valle del Rumblar durante la Prehistoria Reciente". En MoRín, J.; Urbina, D. y Bicho, N. F. (eds.): As Idades do Bronze e do Ferro na Península Ibérica: Actas IV Congresso de Arqueologia Peninsular (Faro, 2004). Promontoria Monográfica, 9. Faro, pp. 273-287.

CÁmara, J. A. y Molina, F. (2011): “Jerarquización social en el mundo argárico (2000-1300 a. C.)”, Quaderns de Prehistòria i Arqueologia de Castelló, 29, pp. 77-104.

Castro, P.; Lull, V. y Micó, R. (1996): Cronología de la Prehistoria Reciente de la Peninsula Ibérica y Baleares (c. 2800-900 cal ANE). BAR Intern. Ser., 652. Oxford: Archaeopress.

Cebrián, R. (2008/09): "Una aproximació al poblament en la vall del riu Gorgos (La Marina Alta, Alacant) del Neolítica a l'Edat del Bronze", Recerques del Museu d'Alcoi, 17-18, pp. 139-164.

Cerdè, F. (1994): "El ir mil.leni a la Foia de Castalla (Alacant). Excavaciones arqueològiques a la Foia de la Perera (Castalla)", Recerques del Museu d'Alcoi, 3, pp. 95-110.

Chapman, R. W. (1990): Emerging Complexity: The Later Prehistory of South-East Spain, Iberia and the West Mediterranean. Cambridge: cup.

De Pedro, M.a J. (1998): La Lloma de Betxí (Paterna, Valencia). Un poblado de la Edad del Bronce. Trabajos Varios del sip, 94. Valencia. 
De Pedro, M. a J. (2010): "Cuevas, fosas y cistas. Evidencias funerarias del II milenio a. C. en tierras valencianas. En torno al Argar y el Bronce Valenciano". En Pérez, A. y Soler, B. (coords.): Restes de vida, restes de mort. La mort a la Prehistòria. Valencia: Diput. de Valencia-Museo de Prehistoria de Valencia, pp. 55-72.

De Pedro, M. a J. y Martí, B. (2004): "Los poblados de la Cultura del Bronce Valenciano". En García, R. y Morales, F. J. (coords.): La Peninsula Ibérica en el II milenio a. C.: poblados y fortificaciones. Cuenca: UCLM, pp. 299-334.

De Pedro, M. a J.; Ripollés, E. y Fortea, L. (2015): "El territorio. Hacia una definición del espacio social". En De Pedro, M.a J. y Soler, B. (eds.): Vivir junto al Turia hace 4000 años. La Lloma de Betxí. Valencia: sip, pp. 45-51.

De Pedro, M. a J. y Soler, B. (2015): Vivir junto al Turia hace 4000 años. La Lloma de Betxí. Valencia: Museo de Prehistoria.

Esquembre, M. A. (1997): Asentamiento y territorio. La Prehistoria en los municipios de la Biar, la Canyada de Biar, Camp de Mirra, Beneixama y Banyeres de Mariola. Villena: Fund. José María Soler.

Esquembre, M. A. y Simón, J. L. (2001): “Consideraciones en torno al poblamiento de la Edad del Bronce en la Marina Alta", Archivo de Prehistoria Levantina, XxIv, pp. 199-222.

FAIRÉN, S. (2001): "Simas, abrigos y graneros: sobre el uso de las cuevas en la comarca de l'Alcoià", Recerques del Museu d'Alcoi, 10, pp. 73-82.

Feinman, G. M. (2011): "Size, Complexity, and Organizational Variation: A Comparative Approach", Cross-Cultural Research, 45, pp. 37-58.

Fernández-Posse, M. D.; Gilman, A.; Martín, C. y Brodsky, M. (2008): Las comunidades agrarias de la Edad del Bronce en La Mancha oriental (Albacete). Bibliotheca Praehistorica Hispana, xxv. Madrid: csic.

García Atiénzar, P. (2017): "La secuencia crono-cultural del yacimiento de Peńón de la Zorra (Villena, Alicante)". En Barceló, J. A.; Bogadonovic, I. y Morell, B. (eds.): IberCrono. Cronometrías para la Historia de la Peninsula Ibérica. Actas Congreso de Cronometrías para la Historia de la Peninsula Ibérica (Barcelona, 2016). Barcelona: CEUR-ws, pp. 128-142.

García Borja, P. (2004): "Avanç sobre el poblament de la vall del Cànyoles durant l'Edat del Bronze”. En Hernández Alcaraz, L. y Hernández Pérez, M. S. (eds.): La Edad del Bronce en tierras valencianas y zonas limitrofes (Villena, 2002). Villena: Inst. Cultura J. Gil-Albert, pp. 347-350.
García Borja, P.; Carrión, Y.; López, J.; Morales, J. V.; Pardo, S.; Pérez, F.; Pérez, G.; Román, D.; Sañudo, P. y Verdasco, C. (2011): "Les ocupaciones prehistòriques de la cueva de la Diabla (Ayora, València)", Saguntum, 43, pp. 33-54.

García Guardiola, J. (2006): Arqueología, patrimonio y paisaje. El valle de los Alhorines (Villena, Alicante). Colección Vestigium, 2. Villena: Museo Arqueológico.

Gil-Mascarell, M. (1995): "Algunas reflexiones sobre el Bronce Valenciano", Saguntum, 28, pp. 63-73.

Gilman, A. (1981): "The development of social stratification in Bronze Age Europe", Current Anthropology, 22, pp. 1-23.

GusI, F. y OlÀria, C. (2014): Un asentamiento fortificado del Bronce medio y Bronce final en el litoral mediterráneo: Oropesa la Vella (Oropesa del Mar, Castellón, España). Castellón: Diput. de Castellón.

Hernández, M. S. (1986): "La cultura de El Argar en Alicante. Relaciones temporales y espaciales con el mundo del Bronce Valenciano". En Homenaje a L. Siret 1934-1984 (Cuevas de Almanzora, 1984). Sevilla: Junta de Andalucía, pp. 341-350.

Hernández, M. S. (1997): "Desde la periferia de El Argar. La Edad del Bronce en las tierras meridionales valencianas", Saguntum, 30, pp. 93-114.

Hernández, M. S. (2002): "El poblamiento prehistórico en Albacete. Estado actual y perspectivas de futuro". En II Congreso de Historia de Albacete. Albacete: Inst. Estudios Albacetenses, pp. 11-20.

Hernández, M. S.; García, G. y Barciela, V. (2016): Cabezo Redondo (Villena, Alicante). Alicante: Univ. de Alicante-Ayto. de Villena.

Hernández, M. S.; Mataix, J. J. y Ferrer, P. (2015): "Reflexiones en torno a los enterramientos de la Edad del Bronce en las tierras valencianas. A propósito de la Cova de l'Esbarzer (la Vall de la Gallinera, Alacant)", Alberri, 25, pp. 93-110.

Jover, F. J. (1999): Una nueva lectura del 'Bronce Valenciano'. Alicante: Univ. de Alicante.

Jover, F. J. y López, J. (1999): “Campesinado e historia. Consideraciones sobre las comunidades agropecuarias de la Edad del Bronce en el Corredor del Vinalopó", Archivo de Prehistoria Levantina, xxIII, pp. 233-257.

Jover, F. J. y López, J. A. (2016): "Nuevas bases para el estudio de las comunidades campesinas de la Edad del Bronce en el Levante peninsular: el asentamiento de Terlinques (Villena, Alicante)". En Del neolític a l'edat del bronze en el Mediterrani occidental. Estudis 
en Homenatge a B. Martí Oliver. Trabajos Varios del sIP, 119. Valencia, pp. 427-449.

Jover, F. J.; López, J. A. y García-Donato, G. (2014): "Radiocarbono y estadística bayesiana. Aportaciones a la cronología de la Edad del Bronce en el extremo oriental del sudeste de la península Ibérica”, Saguntum, 46, pp. 41-69.

Jover, F. J.; Moratalla, J.; Martínez, S. y Segura, G. (2017): "Poblados, cuevas, cobertizos y refugios de la Edad del Bronce: la aportación del cerro de los Purgaticos (La Canyada, Alicante)", Saguntum, 49, pp. 7-29.

Legarra, B. (2013): "Estructura territorial y estado en la cultura argárica", Menga, 4, pp. 149-171.

López Padilla, J. A. (2011): Asta, hueso y marfil. Artefactos óseos de la Edad del Bronce en el Levante y Sureste de la Península Ibérica (c. 2500-c. 1300 cal AC). Serie Mayor, 9. Alicante: MARQ.

López Sáez, J. A.; Alba, F.; NÁJera, T.; Molina, F.; Pérez, S. y Sabariego, S. (2014): "Paleoambiente y sociedad en la Edad del Bronce de La Mancha: la Motilla del Azuer", Cuadernos de Prehistoria y Arqueologia Univ. de Granada, 24, pp. 391-422.

LulL, V. (1983): La cultura de El Argar. Un modelo para el estudio de las formaciones económico-sociales prehistóricas. Madrid.

LulL, V. y Estévez, J. (1986): "Propuesta metodológica para el estudio de las necrópolis argáricas”. En Homenaje a L. Siret 1934-1984 (Cuevas del Almanzora 1984). Sevilla, pp. 441-452.

Lull, V.; Micó, R.; Rinuete, C. y Risch, R. (2010): "Metal and social relations of production in the $3 \mathrm{rd}$ and 2nd millennia $\mathrm{BC}$ in the southeast of the Iberian Peninsula", Trabajos de Prehistoria, 67 (2), pp. 323-347.

Lull, V.; Micó, R.; Rinuete, C. y Risch, R. (2011): "El Argar and the Beginning of the Class Society in the Western Mediterranean". En Hansen, S. y MüLLER, J. (eds.): Sozialarchäologische Perspektiven: Gesellschaftlicher Wandel 5000-1500 v. Chr. Zwischen Atlantik und Kaukasus. Berlin, pp. 381-414.

Lull, V.; Micó, R.; Rinuete, C. y Risch, R. (2016): "Argaric sociology: sex and death", Complutum, 27 (1), pp. 31-62.

Martí, B. (1983): El nacimiento de la agricultura en el Pais Valenciano. Cultura Popular. Valencia: Univ. de Valencia.

Martín, C.; Fernández-Miranda, M.; FernánDeZ-Posse, M. D. y Gilman, A. (1993): "The Bronze Age of La Mancha”, Antiquity, 67, pp. 23-45.
Martínez Monleón, S. (2014): El Argar en el Bajo Segura y Bajo Vinalopó. Patrón de asentamiento en un territorio de frontera. Villena: Fund. José María Soler.

Martínez Navarrete, I. (1989): Una revisión crítica de la prehistoria española. La Edad del Bronce como paradigma. Madrid: Siglo XxI.

Martínez Pérez, A. (1985): "La Cultura del Bronce Valenciano en la Ribera", Al-Gezira, 1, pp. 13-111.

McClure, S. B.; García, O.; Roca, C.; Culleton, B. y Kennett, D. (2011): "Osteological and paleodietary investigation of burials from Cova la Pastora, Alicante, Spain”, Journal of Archaeological Science, 38, pp. 420-428.

Mejías, M.; Benítez de Lugo, L.; López, J. A. y EsTEBAN, C. (2015): Arqueología, hidrogeología y medio ambiente en la Edad del Bronce en La Mancha. La Cultura de las Motillas. Madrid: IGME.

Moraño, I. y García, J. M. (1991): "Introducción al estudio del poblamiento durante la Edad del Bronce en el Sur de la Plana Baixa (Castelló)", Boletín de la Asociación Arqueológica de Castellón, 9-11, pp. 13-67.

Nájera, T. (1984): La Edad del Bronce en La Mancha occidental. Tesis Doctorales de la Universidad de Granada, 458. Granada.

Nájera, T.; Jiménez, S.; Molina, F.; Delgado, A. y LAFFranchi, Z. (2012): "La aplicación de los métodos de la Antropología Física en un yacimiento arqueológico: la Motilla del Azuer", Cuadernos de Prehistoria y Arqueología Univ. de Granada, 22, pp. 149-183.

NÁjera, T. y Molina, F. (2004): "Las Motillas: Un modelo de asentamiento con fortificación central en la llanura de La Mancha”. En García, M. R. y MorALES, J. (eds.): La Peninsula Ibérica en el II milenio a. C.: poblados y fortificaciones. Cuenca: UCLM, pp. 173-214.

Navarro, J. F. (1982): "Materiales para el estudio de la Edad del Bronce en el valle medio del Vinalopó (Alicante)", Lucentum, I, pp. 19-70.

Navarro, J. F. (1986): "La Lloma Redona”. En Arqueología en Alicante 1976-86. Alicante, pp. 102-103.

Nocete, F. (1989): El espacio de la coerción. La transición al estado en las campiñas del Alto Guadalquivir (España) 3000-1500 a. C. BAR Int. Ser., 492. Oxford: Archaeopress.

Nocete, F. (1996): "Un modelo de aplicación de análisis multivariante a la prospección arqueológica: $\mathrm{La}$ definición de la Unidad Geomorfológica donde se establece el Asentamiento", Arqueología Espacial, 15, pp. 7-35. 
Palomar, V. (1995): La Edad del Bronce en el Alto Palancia. María de Luna, vi. Segorbe.

Pascual, J. Ll. (1990): “L’Edat del Bronze en la comarca del Comtat". En Ayudas a la investigación 1986-87. Alicante: Inst. Cultura J. Gil-Albert, t. III, pp. 83-103.

PÉrez Botí, G. (2000): “Una aproximación a la Edad del Bronce en la cabecera del río Polop (Alcoi, Alacant)", Recerques del Museu d'Alcoi, 9, pp. 97-106.

Ramos, A. (2013): "Villages of wealth and resistance in paradise: Millaran and Argaric chiefdoms in the Iberian Southeast”. En Berrocal, M. C.; García, L. y Gilman, A. (eds.): The Prehistory of Iberia. Debating Early Social Stratification and the State. New York, pp. 74-98.

Ribera, A. y Pascual, J. (1997): "Els poblats de l'Edat del Bronze d'Ontinyent i la Vall d'Albaida Occidental (i III). Analisi i consideracions", Alba, 12, pp. 25-78.

Ripollés, E. (1994): "Les Raboses (Albalat dels Tarongers): Un yacimiento de la Edad del Bronce en el Baix Palancia", Archivo de Prehistoria Levantina, XxI, pp. 47-82.

Risch, R. (2002): Recursos naturales, medios de producción y explotación social. Un análisis económico de la industria litica de Fuente Álamo (Almería) 2250-1400 antes de nuestra era. Iberia Archaeologica, 3. Mainz.

Schubart, H. (1975): Die Kultur der Bronzezeit im Südwesten der Iberischen Halbinsel. Madrider Forschungen 9 . Berlin.

Schummacher, T. X. (2012): "El marfil en España desde el Calcolítico al Bronce Antiguo. Resultados de un proyecto de investigación interdisciplinar”. En
Banerjee, A.; López, J. A. y Schuhmacher, T. X. (eds.): Marfil y elefantes en la Peninsula Ibérica y el Mediterráneo occidental (Coloquio internacional, Alicante, 2008). Iberia Archaeologica. Elfenbeinstudien. Faszikel 1. Mainz: DAI-MARQ, pp. 45-68.

Simón, J. L. (1998): La metalurgia prehistórica valenciana. Trabajos Varios sip, 93. Valencia.

Soriano, S. (2004): "El patrón de asentamiento durante la Edad del Bronce en el Camp d'Alacant”. En Hernández Alcaraz, L. y Hernández Pérez, M. S. (eds.): La Edad del Bronce en tierras valencianas y zonas limitrofes (Villena 2002). Alicante: Inst. Cultura J. Gil-Albert, pp. 263-268.

Steponaitis, V. P. (1981): "Settlement hierarchies and political complexity in non-market societies: the formative period of the Valley of Mexico", American Anthropologist, 83, pp. 320-363.

Tarradell, M. (1950): "La Península Ibérica en la época de El Argar”. En v Congreso de Arqueología del Sudeste Español. Almería, pp. 72-85.

Tarradell, M. (1963): El País Valenciano del Neolitico a la iberización. Ensayo de sintesis. Valencia: Univ. de Valencia.

Tarradell, M. (1965): "El problema de las diversas áreas culturales de la Península Ibérica en la Edad del Bronce”. En Ripoll, E. (ed.): Miscelánea en Homenaje al abate H. Breuil (1877-1961). Barcelona: Diput. Prov.-Inst. Prehistoria y Arqueología. Barcelona, vol. II, pp. 423-430.

Trelis, J. (1992): "Excavaciones en el yacimiento de la Edad del Bronce de Mas del Corral (Alcoy-Alicante)", Recerques del Museu d'Alcoi, 1, pp. 85-89. 
